Discussion Papers of the

Max Planck Institute for

Research on Collective Goods

2020/4

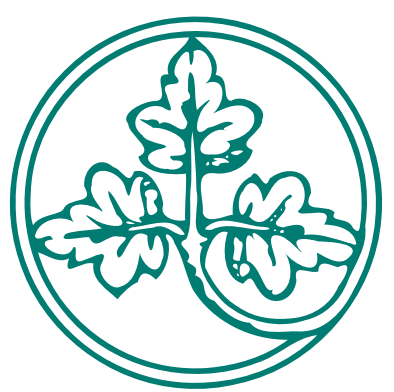

Volunteering at the Workplace under Incomplete Information: Teamsize Does Not Matter

Adrian Hillenbrand

Tobias Werner

Fabian Winter 


\title{
Volunteering at the Workplace under Incomplete Information: Teamsize Does Not Matter
}

\author{
Adrian Hillenbrand / Tobias Werner / Fabian Winter
}

February 2020 


\title{
Volunteering at the Workplace under Incomplete Information: Teamsize Does Not Matter
}

\author{
Adrian Hillenbrand* Tobias Werner`, Fabian Winter ${ }^{\ddagger}$
}

February 10, 2020

\begin{abstract}
Volunteering is a widespread allocation mechanism at the workplace and emerges naturally in open-source software development, the generation of online knowledge platforms, and to some extent in "agile" work environments. Using a field experiment with 8 treatments and close to 2,800 workers on an online labor market, we study the effect of team size on volunteering at the workplace under incomplete information. In stark contrast to the theoretical predictions, we find no effect of team size on volunteering behavior. With the use of our control treatments, we can show that workers react to free-riding incentives provided by the volunteering setting in general, but do not react strategically to the team size. We show that the result is robust to several further factors.
\end{abstract}

\section{Introduction}

Volunteering is an important feature of the fundamental organization of firms. In various situations, tasks and resources are not allocated among employees by some supervisor, but rather employees have to solve the allocation process by themselves. We argue that in those situations volunteering arises frequently in an organizational context. Consider, for example,

\footnotetext{
${ }^{*}$ Max Planck Institute for Research on Collective Goods, Kurt-Schumacher-Strasse 10, 53113 Bonn, Germany, hillenbrand@coll.mpg.de

${ }^{\dagger}$ Düsseldorf Institute for Competition Economics (DICE), University of Duesseldorf, Universitätsstr. 1, 40225 Düsseldorf, Germany, werner@dice.hhu.de

${ }^{\ddagger}$ Max Planck Institute for Research on Collective Goods, Kurt-Schumacher-Strasse 10, 53113 Bonn, Germany, winter@coll.mpg.de
} 
product development teams within a company. The manager of a team decides that a certain (individually promotion-irrelevant) task has to be completed and delegates it to a member of his team. Naturally, the completion of the task requires time and effort, such that each team member would prefer another person to finish it. If the task is completed, the product advances, which yields a higher reputation to the team in the organization and may improve the overall performance of the firm in the market. This, in turn, benefits the whole product team as it may improve wages or the job prospects of all team members. In contrast to the situation where the manager delegates the task to a specific person, in this case the manager only communicates that the task has to be completed, but does not explicitly direct one or more team members to do so. It's simply the team members' decision who completes the task. In these situations, volunteering is a natural allocation mechanism, which we want to examine in this paper.

While the described allocation process might seem inefficient in comparison to the direct delegation of the task by the superior to a specific team member, situations like this still occur frequently - and apparently for good reasons - in organizational contexts. For example, many duties in academia are allocated based on voluntary decisions (Babcock et al. 2017), just as the development of open-source software projects (Johnson 2002), the contribution to network technology (Lee et al.|2007), the creation of online knowledge platforms like Wikipedia (Zhang and Zhu 2011), or modern work allocation mechanisms like the so-called agile project methods, which are commonly used in software development (Hoda et al. 2018).

The volunteering mechanism apparently does have attractive qualities. Not least, it may reduce the organizational overhead required to organize task allocations. Yet, volunteering in an organizational context is usually not an altruistic act towards others, but often the individually profit-maximizing response to an organizational problem (Murnighan et al. 1993. Wook Kim and Murnighan 1997). Economic (game) theory thus suggests that the volunteering mechanism also introduces two important obstacles. For one, it creates a coordination problem that has to be resolved by the workers. More importantly, however, the individual incentive structure of the firm may give rise to a social dilemma: while working is costly, but the exact costs are usually unknown, the fruits of labor may be enjoyed by all team members. This, in turn, leads to the famous Volunteer's Dilemma (Diekmann 1985). 
The strategic analysis of the Volunteer's Dilemma closely resembles a number of relevant factors for the success of volunteering choices in organizations. First, companies and the teams within the company may be of various sizes, which in turn has an influence on the degree of volunteering. This has been robustly shown in various lab and field experiments on the topic (Diekmann 1986, Franzen 1995, Goeree et al. 2017, Kopányi-Peuker 2019, Latané and Nida 1981, Przepiorka and Berger 2016, Barron and Yechiam 2002). Second, the individual costs of volunteering might be different for different workers, which also affects individual volunteering choices. (Diekmann 1993, Przepiorka and Berger 2016). While lab evidence suggests that both factors negatively affect the provision of voluntary work, the prevalence of volunteering in real-world organizations is striking. This begs the question whether economic theory and experimental results from the lab are equally problematic in real-world work environments.

In this paper, we scrutinize economic arguments and the existing empirical evidence on volunteering by putting them to a test in real-life workplaces. In a large-scale field experiment with almost 2,800 workers, we analyse the prevalence of volunteering at the workplace and the effect of group size on volunteering behavior. Our main treatment manipulation is thus varying the group size of work teams: we compare the willingness to volunteer for a specific task when working alone to working in small, medium, and large groups of up to 400 workers. In our field experiment we act as an employer in an online labor market and offer a simple rating task to the online workers. After finishing the task, we offer each participant the opportunity to continue working on the task. If at least one person in a group volunteers, each team member receives an additional bonus payment, which resembles the Volunteer's Dilemma. In this second round, we inform our workers about the time it has taken them to perform the task and how long it has taken the others.

Our experimental setting allows us to study the causal effect of differences in team size. By creating a natural yet anonymous work environment we can exclude reputational concerns as well as personal relationships between workers, which would impede the analysis of volunteering at more traditional workplaces. The online labor market provides a unique ecosystem with tight control over the environment, while allowing us to precisely measure individual opportunity costs and other important variables. 
Further, our design allows us to relax two unrealistically restrictive assumptions in earlier experiments: neither the individual costs nor the exact group size is usually known when people face volunteering decisions in the real world. Particularly in larger organizations, workers are usually only vaguely informed about the exact number of other workers. Even within a smaller product team, uncertainty about the set of potential volunteers is likely, for instance if volunteering is not beneficial for parts of the team or the fluctuation in the team is high. Furthermore, entering the volunteering situation might be an individual choice made by each team member. This can create another source of uncertainty if this endogenous decision is not common knowledge. We will refer to this as population uncertainty, where everyone only has an intuition about the number of potential volunteers, but the exact number is unknown. The concept of population uncertainty was first introduced by Myerson (1998, 2000), who showed that it has profound implications on the strategic interaction of the players in a game. His results have been applied to problems in political science (Nunez 2010) and macroeconomics (Makris 2008). Also, in other contexts like auctions (Harstad et al. 1990), coordination games (Ioannou and Makris 2017), contests (Lim and Matros 2009, Boosey et al. 2017), the enforcement of social norms (Winter and Franzen 2017, Au et al. 1998), or price competition (Ritzberger 2009), population uncertainty has been shown to be an influential factor. Most related to our research question, Hillenbrand and Winter (2018) show that in a Volunteer's Dilemma setting population uncertainty can, to some extent, mitigate the dilemma and increases volunteering compared to a certain group size. Our experiment explicitly varies the team sizes and the information about it for our workers.

Besides population uncertainty, the costs of volunteering usually differ between workers. Those differences can arise due to variations in skills, which enable certain workers to complete a specific task with less effort. Furthermore, the outside option might vary between the workers, which has an implicit effect on their costs. Arguably, heterogeneity in the costs is rather the norm than the exception. While most of the literature either ignores heterogeneity of costs or simply assumes that the individual costs are common knowledge, this assumption is clearly overly restrictive in realistic work environments. There typically exists a substantial degree of uncertainty about the costs of volunteering. This is particularly important in bigger organisations, since people tend to volunteer less in larger groups in the presence of cost uncertainty (Weesie 1994, Healy and Pate 2018). The variation in costs in our experiment 
naturally arises from our field setting, in which workers vary in skill and/or opportunity costs of completing the task.

Our work thus brings together population uncertainty as well as cost uncertainty within the volunteering process. We will contribute to this literature by (i) a rigorous theoretical investigation of volunteering under population and cost uncertainty, and (ii) by testing the theoretical results in a large-scale field experiment in an online workplace.

The results of this empirical test in the field stand in stark contrast to the game-theoretical predictions and results from earlier laboratory studies. We find no support for the hypothesis that population uncertainty or the group size have an influence on the volunteering decision of our workers. Also, the costs of volunteering seem to play a negligible role given our proposed cost measure. We show that our results are robust to multiple potential factors. Comparing the results of the Volunteer's Dilemma to a similar task without strategic interaction, i.e., where each worker decides to volunteer on his own and is paid accordingly, helps us to rule out several possible explanations: workers are less likely to volunteer if volunteering is not compensated, suggesting that the effort is indeed costly. Also, they are more likely to volunteer if their payment only depends on their own actions, suggesting that they make a difference between strategic and non-strategic situations.

Our results thus suggest that managerial decisions to favor volunteering over delegation might be justified in larger groups also, even though theoretical reasoning would predict otherwise. Importantly, according to our results, this is true even in the absence of reputation concerns or other punishment mechanisms for non-volunteering. However, the results also open up questions for future research, in particular why workers do not react to group sizes, while lab participants usually do.

The remainder of the paper is structured as follows. In Section 2, we develop a formal model of volunteering under cost and population uncertainty by extending the work by Weesie (1994) and Hillenbrand and Winter (2018). Following this, we explain the experimental design of the field experiment in Section 3 and the resulting pre-registered hypotheses in Section 4$]^{1}$ Our

\footnotetext{
${ }^{1}$ The pre-registration of the field experiment and the main hypothesis can be found under http://dx.doi. org/10.17605/OSF.IO/7RQVH. Ethical approval was obtained from the German Association for Experimental Economic Research e.V. and can be accessed under https://gfew.de/ethik/Ft9eR5SK.
} 
hypotheses are empirically tested in Section 5. Section 6 discusses our findings and concludes the paper.

\section{A Formal Model of Volunteering at the Workplace}

In this section, we will lay out a general model of volunteering under cost and population uncertainty and apply it to our context of volunteering at the workplace. The model captures three important characteristics of volunteering decisions in the workplace. First, volunteering is chosen simultaneously and without communication, which sets a lower bound for our purposes. Second, there is heterogeneity in, and incomplete information about, the costs of volunteering; and third, the group size may be uncertain, which captures our definition of population uncertainty.

We will rely on the Volunteer's Dilemma (Diekmann 1986) as our theoretical workhorse. With its numerous variations, it has been examined in several experimental studies, and the main predictions, in particular the diffusion of responsibility effect, has been shown to be fairly robust (Diekmann 1986, Franzen 1995, Goeree et al. 2017, Kopányi-Peuker 2019). Also, in different field environments, the predictions from the Volunteer's Dilemma turn out to be robust (Latané and Nida 1981, Przepiorka and Berger 2016, Barron and Yechiam 2002). Given the vast empirical support for the model (see, e.g., Latané and Nida 1981, Przepiorka and Berger 2016, Barron and Yechiam 2002), one might expect it to be useful in providing predictions in our setting of an online workplace as well.

Volunteer's Dilemma The Volunteer's Dilemma was developed by Diekmann (1985) and formalizes the findings of Darley and Latané (1968) on the diffusion of responsibility as a social dilemma in a formal model. In this original version of the model, a fixed number of participants face the same cost of volunteering. A single volunteer in the group is sufficient to produce a benefit for all its members, which no one receives in case no volunteer can be found. Furthermore, the individual benefit from the public good is greater than the costs of volunteering. This gives rise to the dilemma situation of the game: If there were another volunteer in the game for sure, workers would never volunteer. However, given that the benefit is greater than the costs, workers would prefer to volunteer if all of their colleagues defected. 
Formally, we have a game with $N$ players who simultaneously decide to volunteer $\left(a_{i}=V\right)$ or to defect $\left(a_{i}=D\right)$ with benefits $b$ and $\operatorname{costs} c$ where $b>c$. The payoff $\pi_{i}$ of worker $i$ when $X_{-i}$ others volunteer is

$$
\pi_{i}= \begin{cases}0 & \text { if } a_{i}=D \text { and } X_{-i}=0 \\ b & \text { if } a_{i}=D \text { and } X_{-i}>0 \\ b-c & \text { if } a_{i}=V .\end{cases}
$$

The symmetric Volunteer's Dilemma has a unique mixed-strategy equilibrium with the intuitive property that the individual probability of volunteering is decreasing in the number of players in the game (Diekmann 1985). Thus, the model captures the "diffusion of responsibility" effect of a decreasing probability to volunteer in larger groups.

Incomplete Information about Costs Arguably, costs of volunteering are usually not homogeneous for all workers, and only in rare cases are the costs known exactly. We therefor include ideas from the volunteering models with heterogeneous effort costs (Diekmann 1986), as well as incomplete information about the distribution of costs (see Weesie (1994) for a formal model and Healy and Pate (2018) for recent experiment evidence). Our model thus assumes privately known and heterogeneous $\operatorname{costs} c_{i}$ and benefits $b_{i}$ for each player $i \in\{1, \ldots, N\}$. In line with Weesie (1994), we assume that $\gamma_{i}:=\frac{c_{i}}{b_{i}}$ follows some arbitrary probability distribution $\gamma \sim \mathscr{F}$ with a continuous probability density function $f$ We will commonly refer to $\gamma_{i}$ as the type of player $i$. Weesie (1994) shows that for a given group size $N$ and some distribution of costs there exists a pure strategy equilibrium where players with low cost-benefit ratios volunteer, while those with a $\gamma_{i}$ above some threshold do not volunteer.

Population Uncertainty We generalize the result by (Weesie 1994) by including population uncertainty in the model. The positive effect of population uncertainty on volunteering has been shown theoretically and experimentally (Peña and Nöldeke 2016, Hillenbrand and Winter 2018). What is unclear so far are its interactions with cost uncertainty.

\footnotetext{
${ }^{2}$ We further assume that the cumulative distribution function (cdf) denoted by $F(\cdot)$ is atomless.
} 
Following the approach of Hillenbrand and Winter (2018), we let the number of workers $n$ be drawn from a discrete probability distribution $h$. The probability mass function is denoted by $h(\cdot)$. Furthermore, let $n \in \tilde{N}=\{2, \ldots, \bar{N}\}$, with $\bar{N} \in \mathbb{N}$ being the largest possible number of workers in the game. Since we are interested in the effect of the mean group size on volunteering, we define $E[n]=N$. Importantly, a fixed group size $\hat{n}$, i.e., a situation without population uncertainty, is then just a special case in this setup with $h(\hat{n})=1$.

\subsection{Equilibrium Predictions}

Our theoretical model generalizes the finding by Weesie (1994) and Hillenbrand and Winter (2018). We thus combine population uncertainty and cost uncertainty in a Volunteers Dilemma. Our main result (Proposition 1) is a generalization of Weesie (1994) with population uncertainty, while the effect of population uncertainty on volunteering (Proposition 2) is an extension of Hillenbrand and Winter (2018), including incomplete information about costs. For the theoretical discussion instead of discussing the full set of potential equilibria, we focus on a pure-strategy equilibrium as in Weesie (1994). Importantly, as he points out, there is no equilibrium in mixed strategies, i.e., where a player of a given type plays $V$ or $D$ with a positive probability. For a more general discussion on possible equilibria in the Volunteer's Dilemma, see Diekmann (1985, 1986), Weesie (1994). The pure-strategy equilibrium that we discuss has some nice properties and makes intuitive sense for an applied setting such as ours. We show that in a Volunteer's Dilemma with incomplete information about costs and population uncertainty there exists an equilibrium where players with cost-benefit ratios below some threshold $\tilde{\gamma}$ volunteer, while those above defect. We further show that this threshold, and thus the individual probability to volunteer, is smaller in situations with a large probability of being in bigger groups.

Proposition 1 (Pure Strategy Nash Equilibrium with Population Uncertainty). Let $\mathscr{F}$ be an arbitrary probability distribution over $\gamma$ with a continuous pdf and an atomless cdf. Let $h$ be a discrete probability distribution over $n$. Then

1.1 There exists a type-specific pure strategy Nash Equilibrium with some threshold $\tilde{\gamma}_{h}$, which depends on $\mathscr{F}$ and $h$. 
1.2 The equilibrium strategy of worker $i$ can be described as

$$
a_{i}^{*}=\left\{\begin{array}{l}
V \text { if } \gamma_{i} \leq \tilde{\gamma}_{h} \\
D \text { if } \gamma_{i}>\tilde{\gamma}_{h}
\end{array}\right.
$$

1.3 Let $j$ and $k$ be two discrete probability distributions describing the stochastic population size of the game. Assume that $j$ first-order stochastically dominates $k$. Define $\tilde{\gamma}_{j}$ as the equilibrium threshold for distribution $j$ and $\tilde{\gamma}_{k}$ as the threshold for the distribution $k$. Then, we have $\tilde{\gamma}_{k}>\tilde{\gamma}_{j}$.

The proof for Proposition 1 can be found in Appendix A. The two take-aways from the proposition are that, first, players volunteer less given a larger probability of being in bigger groups. In other words, an increase in the mean group size decreases volunteering given that the increase is due to a shift in the distribution according to first-order stochastic dominance. Note that this also takes into account an increase in the group size when the size is certain. Second, those players with lower costs should be more likely to volunteer, as $P\left(\gamma_{i} \leq \tilde{\gamma}_{h}\right)=$ $F\left(\tilde{\gamma}_{h}\right)$ describes the probability of an arbitrary player volunteering given $a_{i}^{*}$.

Finally, we are interested in the effect of population uncertainty. Since changes in the expected group size are obviously important, we restrict ourselves to cases where the expected group size is constant, but their distributions are mean preserving spreads of each other: Let $g$ and $z$ be two discrete probability distributions over $n$ and let $g$ be a mean-preserving spread of $z$, i.e., $g$ is more uncertain than $z$, but has the same mean $N$. We then obtain the final theoretical result, namely that higher uncertainty leads to higher volunteering rates. More precisely, higher uncertainty increases the threshold $\tilde{\gamma}_{h}$ and thereby $P\left(\gamma_{i} \leq \tilde{\gamma}_{h}\right)=F\left(\tilde{\gamma}_{h}\right)$.

Proposition 2 (Effect of Population Uncertainty). Let $g$ and $z$ be two discrete probability distributions describing the stochastic population size of the game. Assume that $z$ is a meanpreserving spread of $g$. Define $\tilde{\gamma}_{z}$ as the equilibrium threshold for distribution $z$ and $\tilde{\gamma}_{g}$ as the threshold for the distribution $g$, which we described in Proposition 1. Then, we have $\tilde{\gamma}_{z}>\tilde{\gamma}_{g}$.

For the proof of Proposition 2, see Appendix A. Clearly, this also captures the situation that we look at in our setting, i.e., comparing an uncertain distribution with mean group size of $E[n]=N$ with a certain group size of $N$. 


\section{Experimental Design}

The goal of the field experiment is to study volunteering at the workplace. In order to establish causal claims, we have to maintain a high degree of experimental control. Online labor markets are therefore not only a convenient, but also a particularly useful environment for our experiment. Importantly, it is a regular and natural workplace for our experimental workers, and workers differ in their effort costs. At the same time, it allows us exogenously to set group sizes and manipulate the information workers receive about the group. This further differentiates online labor markets from classical work environments, where workers are usually connected through personal relationships and a common history across and within teams. These factors would impede the identification of the causal effects of group sizes and population uncertainty, making the use of an online labor market crucial for this study.

In a nutshell, the field experiment consists of two stages (see Figure 1). In the first part of the job, workers were invited to work individually on a coding task for a fixed payment. Upon joining the job, the workers were randomly matched to one of eight treatments in which we varied group size and population uncertainty. After completing the first individual task, workers were informed about a second stage. We asked them whether they would like to volunteer in a second round of coding, just like the one they had done before, but with a different payment scheme. This second stage implements the actual Volunteer's Dilemma: Only if at least one worker in the group task volunteered were all group members paid an additional bonus. Finally, all workers had to answer a short questionnaire and then received the payoffs some days after the experiment.

\subsection{Workers and the Online Labor Market}

The field experiment was conducted on clickworker.de, an online crowdsourcing marketplace. Crowdsourcing marketplaces allow people to work on tasks that are usually easy to do for humans, but difficult to automate. Most tasks on such platforms require a couple of minutes to complete and include assignments like the processing of images or the cleaning of data (see Difallah et al. (2015) and Jain et al. (2017) for an overview of common tasks). Online labor markets have become increasingly popular in recent years (Difallah et al. 2015), with 0.5\% of the US adult population working in the "sharing economy" in 2016 (Farrell and Greig 


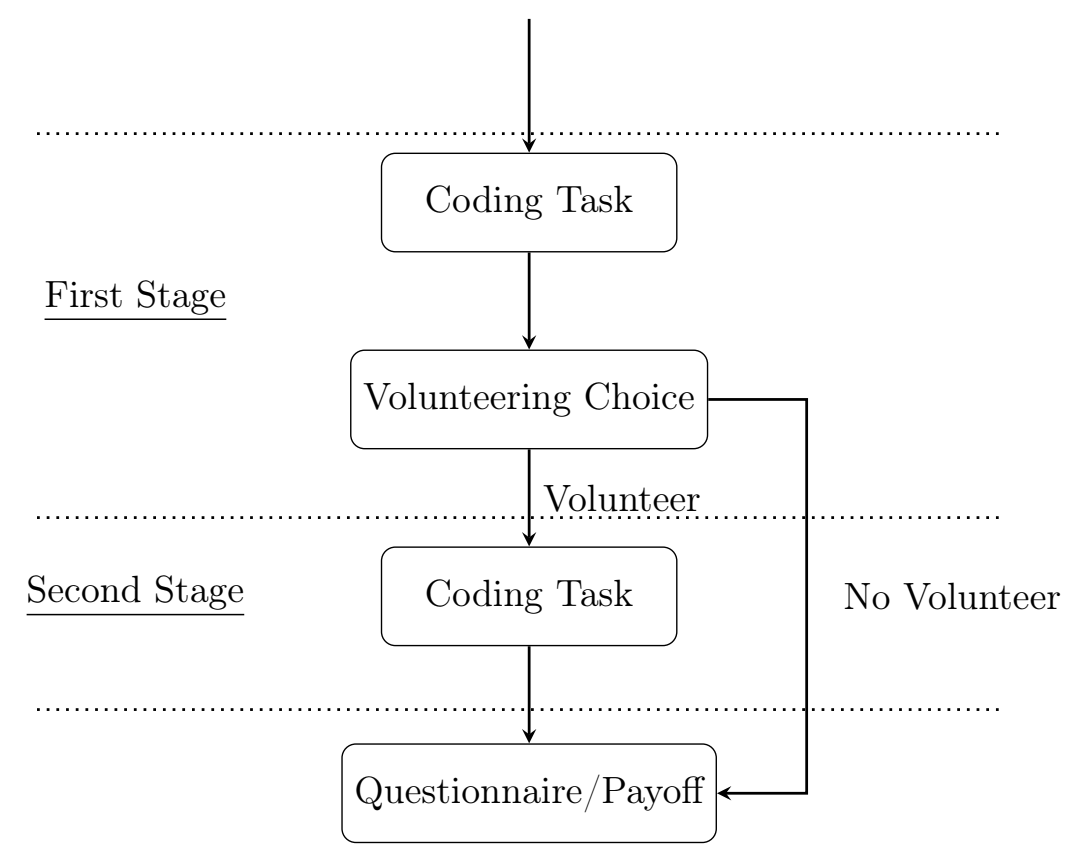

Figure 1: Structure of the experiment.

2017). For many workers, these jobs serve as a substitute for traditional offline work in times of economic downturn (Borchert et al. 2018). For them, online labor markets are a regular work environment, which makes it a perfect testbed to study volunteering at the workplace. Each worker was only allowed to participate once and required to speak German, but we did not impose any further restrictions on the pool of workers. Every active worker on the platform fulfilling those requirements was free to join. In total, 4,412 workers joined the assignment and read the explanation of the task. The assignment was made unavailable once each main treatment had reached 400 workers who had finished the first stage $\mathrm{H}^{3}$ Overall, 2,807 workers finished the first stage of the field experiment and took a decision as to whether they would like to continue working on the task, thus volunteering within their group 4 Altogether, 2,733 workers reached the end of the experiment. For the analysis, we consider only those workers who reached the end of the study. We remain with the treatment composition shown in Table 1. This subset of observations will be used for all subsequent analysis in Section 5, unless stated differently. We obtain a diverse sample with a wide range in age, gender, educational

\footnotetext{
${ }^{3}$ For the baseline treatments, the task was made unavailable after 200 workers had made a volunteering decision.

${ }^{4}$ Some treatments were filled with slightly more than 400 workers, since workers could join the task simultaneously.
} 
status, and employment (also see Table B.2). Of all participants, $29 \%$ report an age between 18 and 25 years, but a sizeable share $(16 \%)$ is also above 45 years of age. Further, the sample consists of self-employed, employed, and unemployed people with various educational backgrounds. In relation to the general population of Germany, the majority of our sample lives in Western Germany (82 \%) and small cities with less than 50,000 inhabitants (39 \%).

Table 1: Number of observations for each treatment.

\begin{tabular}{lcc}
\hline \multirow{2}{*}{ Mean Group Size } & \multicolumn{2}{c}{ Number of Observations } \\
& $\mathrm{PU}\left(s=\frac{N}{3}\right)$ & NPU $(s=0)$ \\
\hline Unincentivized $(N=1)$ & & 192 \\
\hline Incentivized $(N=1)$ & & 196 \\
\hline SMall Group $(N=3)$ & 395 & 396 \\
\hline Medium Group $(N=30)$ & 389 & 393 \\
\hline Big Group $(N=300)$ & 390 & 382 \\
\hline
\end{tabular}

Note: The number of workers for each treatment, with $N$ being the mean group size and $s$ the spread of the population distribution.

\subsection{The Advertised Job}

We offered a standard job to all workers active at that time, via an advertisement on the platform. Importantly, there was no mention of an experiment or similar. The workers were invited to rate user comments from another study, a job that can be frequently found in online labor markets. We provided a short description of the task and informed the workers that they could earn $0.90 €$, the standard wage set by the platform, and how long it would approximately take them to complete the task.

Once they had clicked on our link on the platform, they were redirected to our oTree server (Chen et al. 2016). The workers then received detailed instructions about the task. Crucially, they were made aware that they would be working in a team for this assignment. We clarified that they would first be working alone on the described assignment, and would then be offered a voluntary group project afterwards (see the Appendix for the full instructions).

The Task Workers were asked to evaluate user comments from an online forum. Each comment was made with reference to a picture and possibly comments from other users in 
this online forum. The theme of the picture was always related to migration, refugees, or cultural differences. The workers were asked to rate the comments regarding the expressed sentiment and evaluate whether the comments contained hate speech. The coding scheme and a screenshot of the task can be found in Appendix D.2. In both possible stages of the experiment, 30 distinct comments had to be rated, which were randomly drawn from a set of 11.322 comments 5 All comments had been collected as auxiliary data in a different study and are not part of our research question. Companies and corporations frequently use online labor markets for similar tasks, in order to understand customer comments or reviews better. According to Difallah et al. (2015), those verification and validation tasks belonged to the most common assignments between 2009 and 2014 on Mturk, a US-based competitor of clickworker.de. Thus, we argue that most of the workers were familiar with this type of task and perceived it as a regular assignment rather then as part of a research project. Furthermore, the ratings of the comments will be used in the study for which they had been collected in the first place. Thus, the work was indeed meaningful and important.

\subsection{The Volunteering Decision}

After finishing the first stage of the experiment, we explained to the workers that we needed exactly one volunteer in their group to ensure data quality and to be better able to evaluate the quality of the ratings within their group. We clearly stated that one volunteer within the group was sufficient for the task. Each worker received the offer to volunteer in their team and to continue to work on the task in the second stage. If at least one person in the group volunteered, all members received a bonus payment of $0.90 €$. If no person in the group volunteered, no group member received any bonus. The bonus payment did not increase if more than one person volunteered. Furthermore, we explained to the workers that, even if they had not volunteered themselves, they might still receive the bonus payment if one of their teammates volunteered. To avoid reputation effects, we clarified that their decision would not have an influence on the payoff of the first stage or their user rating in the online labor market. The volunteering decision will be our key dependent variable in the analysis in Section 5 . A screenshot and a translation of the decision screen can be found in Appendix D.3.

\footnotetext{
${ }^{5}$ The rating of the comments was used as a dependent variable in Álvarez-Benjumea and Winter (2018), Álvarez-Benjumea and Winter (2019), and Álvarez-Benjumea (2019).
} 
Implementation of Incomplete Information about Costs We use the time spent in the first part of the job as a cost measure for volunteering. Time spent on a job is a fair measure of opportunity costs, because those who spend more time on the task miss out on more opportunities to work, e.g., on another job on the platform or on more leisure. As we show later, workers differ substantially in the time it takes them to complete the task. Since both parts of the job consist of the same task, the time spent on the first part is also a good predictor for time spent on the second part $(\rho=0.67, \mathrm{p}<.001)$. Workers were made aware of the time it had taken them to complete the first stage.

In accordance with our theoretical model, we induced commonly known beliefs about the distribution of costs of other workers before making the volunteering decision. To this end, we informed them that other workers usually required between 7.5 to 15 minutes to complete the rating of the comments ${ }^{6}$ This gave workers a rough estimate as to whether they had high or low costs of volunteering relative to the other workers.

Implementation of Population Uncertainty Our design includes treatments with a fixed and known group size as well as population uncertainty. To capture population uncertainty, we varied the group size stochastically between a lower and an upper bound. Each outcome was equally likely and workers knew about the potential group sizes. For example, workers were told that they were working in a group of 20 to 40 workers (see details on all treatments below).

\subsection{Treatments}

Volunteer's Dilemma Treatments Workers in our main treatments faced team incentives in the form of a Volunteer's Dilemma. Within the field experiment, we varied the mean group size and the degree of population uncertainty. We varied three group sizes, the SMALL GROUP with 3 workers, the Medium Group with 30 workers, and the BIG Group with 300 workers. In three treatments, these group sizes are certain (no population uncertainty, NPU).

\footnotetext{
${ }^{6}$ These numbers were collected in a pilot study with 100 workers. We showed the workers the 20th and 80th percentile of the time values, but referred to these values as the time it took "most workers". This is obviously a deviation from our theoretical model, which assumes common knowledge of the full distribution. We made this simplification in order not to overburden our workers and to maintain the atmosphere of a normal job.
} 
To capture population uncertainty, we varied the group size stochastically in the Population Uncertainty treatments (PU). Workers faced group sizes with a spread of one-third of the mean group size. That is, small group sizes were determined randomly between 2 and 4 workers, medium group sizes between 20 and 40 workers, and large groups between 200 and 400 workers. Each outcome was equally likely 7

Instructions were adapted accordingly in each group size (see Table 2). Since the information about the group size is the key point in our study, we made sure that the information was clear to workers. The group size was mentioned several times, in particular right before workers made a choice.

Baseline Treatments $(\mathbf{N}=\mathbf{1})$ In order to provide a benchmark for volunteering rates in our setting, we designed two baseline treatments: InCEnTIVIZED and Unincentivized. The basic setup in this study was identical to our main experiment, the difference being that the workers did not face a Volunteer's Dilemma. That is, the instructions were the same as in the Volunteer's Dilemma Treatments, including the fact that workers operated in a team. We pointed out, however, that their actions did not influence the payoffs of their team members, and vice versa.Workers were notified at the end of the first stage that we needed a volunteer to continue to work on the task 8 We varied two conditions. In the INCENTIVIZED condition, subjects were paid the same bonus as in the Volunteer's Dilemma treatments (90 cents) for completing the second part. This condition would provide an upper bound of volunteering without any team incentives. In the UNINCENTIVIZED condition, there was no bonus, which allows us to control for intrinsic or non-monetary motivations to finish the task. The volunteering rates of our main treatment where strategic considerations play a role should then lie between these two conditions.

\footnotetext{
${ }^{7}$ To implement a truly random and independent draw of the group size, there was an individual random draw for each worker. Then, for each worker a random team of the specific size was generated and the worker's payments were based on the actions of these workers. This method is similar to the method used by Boosey et al. (2017).

${ }^{8}$ Note that in the main treatments we explicitly told the workers that we only required a single person to volunteer. In this baseline case, we did not specify how many volunteers are required, but rather that we needed volunteers. In fact, the INCENTIVIZED condition can be understood as a Volunteer's dilemma with a single worker.
} 
Table 2: Main treatments

\begin{tabular}{|c|c|c|}
\hline Mean Group Size & $\mathbf{P U}\left(s=\frac{N}{3}\right)$ & $\operatorname{NPU}(s=0)$ \\
\hline & \multicolumn{2}{|c|}{ "You are in a group with ..." } \\
\hline Small Group $(N=3)$ & " ... 2 to 4 people." & "... exactly 3 people." \\
\hline Medium Group $(N=30)$ & " ... 20 to 40 people." & "... exactly 30 people." \\
\hline Big Group $(N=300)$ & " ... 200 to 400 people." & "... exactly 300 people." \\
\hline
\end{tabular}

\subsection{Questionnaire}

At the end of the field experiment, workers had to answer a questionnaire regarding their economic preferences (Falk et al. 2016) and their sociodemographic/economic background. We kept initial questions to a minimum, so as not to disturb any impression that the experiment was anything other than a normal job..

\section{Hypotheses}

As discussed above, our experimental design is captured by the theoretical model on the Volunteer's Dilemma with Incomplete Information about costs and Population Uncertainty. This allows us to generate hypotheses based on our theoretical analysis in Section 2, All hypotheses and their corresponding statistical test were pre-registered on osf.io in accordance with the AsPredicted.com protocol before conducting the experiment. 9

Hypothesis 1. The volunteering rate decreases in the (mean) group size.

If we consider our treatments with a certain group size and those with an uncertain group size separately, the volunteering rate decreases in the mean group size. This follows from Proposition $1.33^{10}$

Hypothesis 2. Population uncertainty increases the volunteering rate.

\footnotetext{
${ }^{9}$ The pre-registration of our study can be found under http://dx.doi.org/10.17605/OSF.IO/7RQVH. Note that we deviate in the order of the hypotheses and slightly adapted the wording compared to the preregistration.

${ }^{10}$ Note that, in our setting, all changes in the mean group size are due to first-order stochastic dominance.
} 
Proposition 2 clearly also applies to the comparison between a certain group size and an uncertain group size (with the distribution being a mean-preserving spread), and thus we should observe higher volunteering rates under Population Uncertainty than under certainty given a fixed mean group size.

In addition to our two main hypotheses, we generate a hypothesis concerning the interaction of group size and population uncertainty as well as concerning predictions on which workers should volunteer depending on their costs.

Hypothesis 3. The effect of population uncertainty decreases in the mean group size.

Given the parameter choice for our treatment variables, the absolute effect of population uncertainty should decrease for larger groups. This prediction is based on the calculated equilibrium outcomes with a variety of cost-benefit distributions (see Appendix Table B.1). Compared to the statistical power our experimental design offers us, this effect would be small. As other factors, which are not captured by the current theory, might be driving the volunteering behavior, we will still test this hypothesis.

Hypothesis 4. Workers who finished the first stage of the field experiment faster (more slowly) are more (less) likely to volunteer.

Proposition 1 suggests that low-cost workers are more likely to volunteer. As discussed above, we use time spent in the first part of the experiment as a measure of costs. This means that those with lower costs, i.e., those who spent less time in the first part of the experiment, should be more likely to volunteer.

\section{Results}

In this section, we present the results of the field experiment, following the pre-registered hypotheses outlined in Section 4 .

\subsection{Workers are Sensitive to Incentives and Strategic Situations}

To test our first identifying assumption, we would like to establish that the volunteering choice was actually costly. We therefore compare two baseline treatments in which we asked 


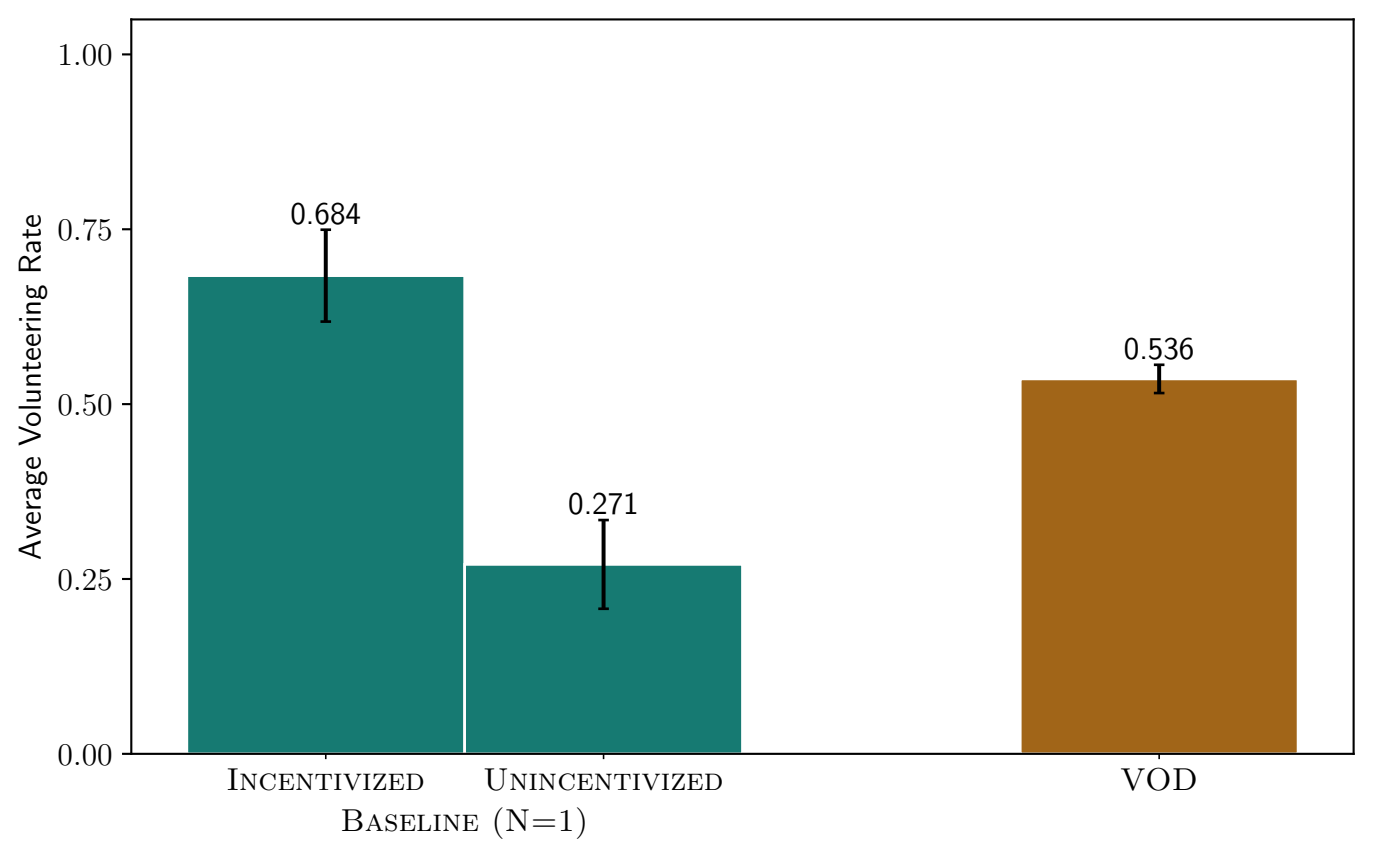

Figure 2: Volunteering rates in the incentivized and the unincentivized baseline treatments in comparison to the main Volunteer's Dilemma (VOD) treatments. The error bars represent $95 \%$-confidence intervals.

participants whether they wanted to volunteer in a second round of coding. In these baseline treatments, the payment only depends on the worker's decision and not on other workers. Thus, strictly speaking, this " $\mathrm{N}=1$ Volunteers Dilemma" is not really a Volunteer's Dilemma. In the INCENTIVIZED condition, participants were paid an additional $0.90 €$ in case they volunteered for a second round of coding; in the UNINCENTIVIZED condition, they were only paid for the first round ${ }^{11}$ The volunteering rate in the INCENTIVIZED version was $68.4 \%$, but only $27.1 \%$ in the UninCENTIVIZED treatment (See Figure 2, $\chi^{2}(1)=66.24, \mathrm{p}<0.001$ ). This allows us to conclude that the real-effort task was in fact perceived as a costly effort, and it establishes the base for the coming results.

Our second identifying assumption was that our participants react to the strategic situation of the Volunteer's Dilemma and show different volunteering rates than in the individual choice situation. We expected that volunteering rates in the main treatments should fall between those in the incentivized and the unincenitivized individual choice condition. This is also the

\footnotetext{
${ }^{11}$ As explained in Section 3 for the main treatments, we only consider those participants who had reached the end of the experiment. Out of 400 participants who started the experiement, we ended up with 388 observations: 196 in the INCENTIVIZED condition and 192 in the UNINCENTIVIZED condition.
} 
case. Pooling the data for all main treatments, the volunteering rate is significantly lower, at $53.6 \%$, than in the INCENTIVIZED condition $\left(\chi^{2}(1)=15.91, \mathrm{p}<0.001\right)$ and significantly higher than in the Unincentivized individual choice condition $\left(\chi^{2}(1)=49.98, \mathrm{p}<0.001\right.$, see Figure 2).

\subsection{No Treatment Differences in the Volunteers Dilemma}

Hypothesis 1 predicted that the volunteering rate decreases in the mean group size. This is clearly not the case (see Figure 3). Volunteering rates are relatively high and statistically indistinguishable with regard to group size. Model 1 in Table C.1 displays a logistic regression pooling the NPU and the PU data. The average marginal effect estimates in Table C.2 show that the effect of group size is small and statistically insignificant at any conventional level. Similarly, comparisons between treatments with $\chi^{2}$-tests provide no significant difference (all $p>0.1)$. We therfore conclude that

Result 1. The volunteering rate does not vary in the mean group size.

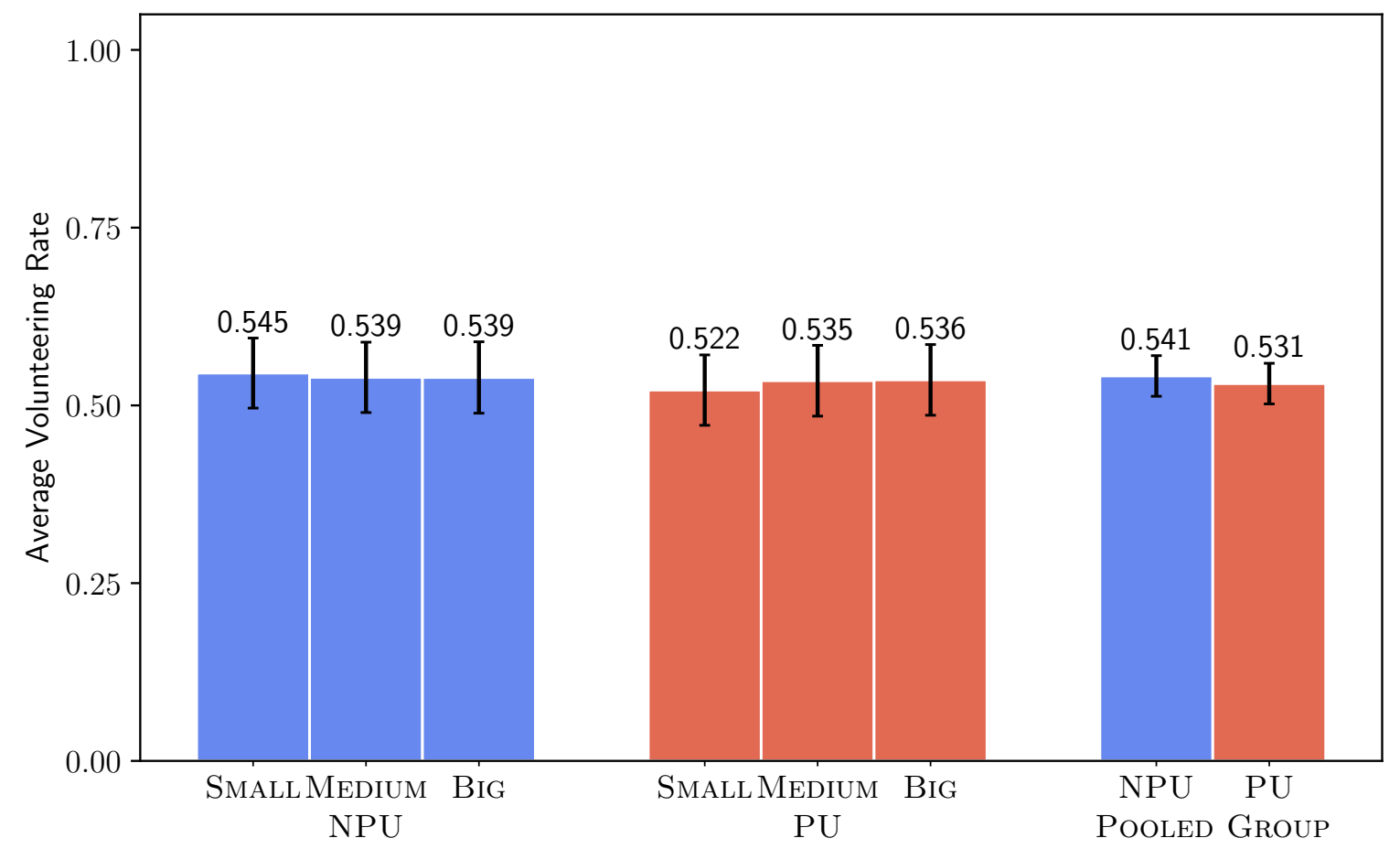

Figure 3: The average volunteering rate across the different mean group size for Population Uncertainty (PU) and no population uncertainty (NPU). The error bars represent 95\%confidence intervals. 
We also find no support for our Hypothesis 2, stating that population uncertainty fosters volunteering if we keep the mean group size constant. Again, Figure 3 is revealing. Model 2 in Table C.1 estimates the main effect of population uncertainty (insignificant). This is also the case if we compare each group size treatment separately $\left(\chi^{2}\right.$-tests, PU vs. NPU; SMALL Group, 0.522 vs. $0.545, \mathrm{p}=0.50, \chi^{2}(1)=0.455$; Medium Group, 0.535 vs. $0.539, \mathrm{p}=0.89$, $\chi^{2}(1)=0.0176$; Big Group, 0.536 vs. $\left.0.539, \mathrm{p}=0.93, \chi^{2}(1)=0.009\right)$. We therefore conclude that

Result 2. Population uncertainty has no statistically significant effect on the volunteering rate.

In Hypothesis 3, we argued that the effect of population uncertainty decreases in the mean group size. We test this hypothesis using a linear probability model with robust standard errors (Table B.3 12 Given that we do not find main effects for population uncertainty or the group size on volunteering, it comes as no surprise that there is no statistically significant interaction effect, either. We therefore conclude that

Result 3. We do not find support for an interaction effect between the mean group size and population uncertainty.

Hypothesis 4 predicts that participants with higher costs are less likely to volunteer. As explained in Section 3, we argue that individual costs of volunteering can be approximated by the time it takes a participant to finish the first stage of the field experiment. Most participants required between 8.18 (20th percentile) and 15.92 minutes (80th percentile) to complete the first stage. Figure $4\left(\right.$ a) presents the estimated distribution of completion times ${ }^{13}$

\footnotetext{
${ }^{12}$ Results from a logistic regression and corresponding average marginal effect estimates can be found in Appendix C.1.

${ }^{13}$ Note that those values are similar to the ones attained in the pilot study, which were shown to the participants as an approximation of the cost distribution, e.g., 7.5 (20th percentile) and 15 (80th percentile). The data includes drastic outliers with some participants having a completion time of more than 16 hours or as little as 2.27 minutes. The participants who took more than 16 hours did not work constantly on the assignment but took long breaks.
} 
(a) TIME

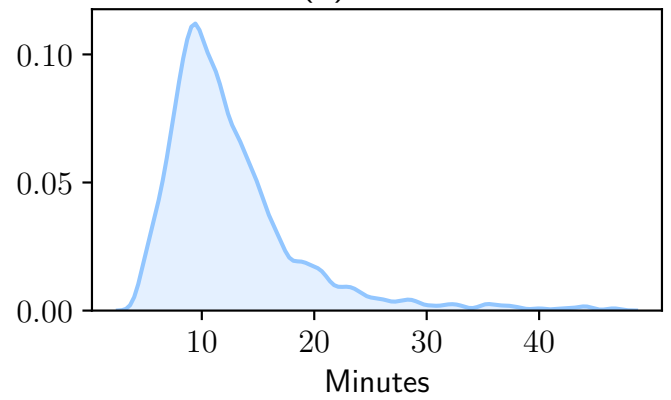

(b) Cost Index

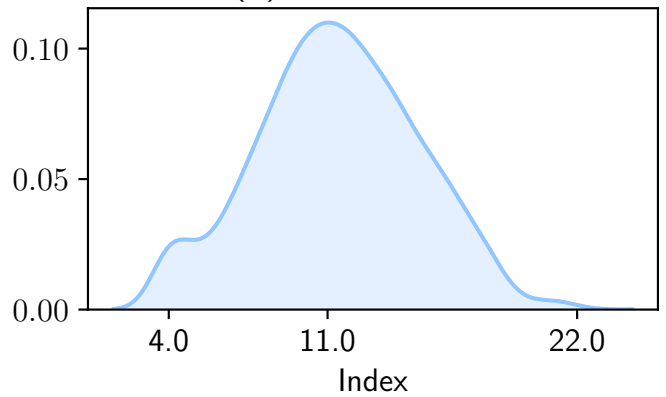

Figure 4: Kernel density estimation of the distributions of the costs of volunteering as measured by the time it took participants to complete the first stage of the field experiment (left) and the subjective effort costs (right). The bandwidth (bw) for TIME is chosen with k-fold cross validation for $k=7$ at $\mathrm{bw}=0.594$ for the Gaussian kernel. For the bandwidth of the CosT InDEX, Silverman's Rule of Thumb was used. We restrict the data in the left plot to values between the 2 nd and 98 th percentile for this visualization.

Our Hypothesis 4 is not supported by the data, since the effect of costs operationalized as time is non-significant. Model 1 in Table 3 shows the results of a logistic regression model and estimates the probability to volunteer as a function of the z-standardized time 14 Importantly, the coefficient of TIME is insignificant 15

As an additional measure of subjective costs, we constructed a z-standardized additive index from several control questions in our post-experimental questionnaire. We asked participants on a 7 -point Likert scale whether they perceived the task as exhausting ( $\mu=3.02)$, interesting ( $\mu=2.89$, reverse-coded), or emotionally challenging $(\mu=2.77)$, and whether it was important to them to contribute to "better data quality" ( $\mu=2.75$, reverse-coded) ${ }^{16}$,

The subjective costs have a substantially meaningful and highly statistically significant negative effect on the probability to volunteer (see Model 2 and 3 in Table 3 and Table B.4. We therefore conclude that

Result 4. The probability to volunteer decreases in the subjective costs of volunteering.

\footnotetext{
${ }^{14}$ We deviate from our pre-registration here in that we focus on costs and thus consider the time and subjective costs, but not task experience and platform experience. The pre-registered analysis can be found in Table C.3 in Appendix C.1.

${ }^{15}$ This is also the case for the estimated average marginal effect, which can be found in Table B.4 in the Appendix.

${ }^{16}$ All questions have been answered on a Likert scale between 1 ("Strongly disagree") and 7 ("Strongly agree").
} 
Table 3: Logistic regression to estimate the volunteering choice as a function of different cost measures

\begin{tabular}{|c|c|c|c|}
\hline & \multicolumn{3}{|c|}{ Dependent variable: } \\
\hline & \multicolumn{3}{|c|}{ Volunteering Choice } \\
\hline & $(1)$ & $(2)$ & $(3)$ \\
\hline Time & $\begin{array}{l}-0.056 \\
(0.052)\end{array}$ & & $\begin{array}{c}0.087 \\
(0.082)\end{array}$ \\
\hline Cost Index & & $\begin{array}{c}-0.225^{* * *} \\
(0.068)\end{array}$ & $\begin{array}{c}-0.224^{* * *} \\
(0.068)\end{array}$ \\
\hline Constant & $\begin{array}{c}0.144^{* * *} \\
(0.041)\end{array}$ & $\begin{array}{c}0.617^{* * *} \\
(0.068)\end{array}$ & $\begin{array}{c}0.618^{* * *} \\
(0.068)\end{array}$ \\
\hline Observations & 2,345 & 974 & 974 \\
\hline Log Likelihood & $-1,618.601$ & -626.361 & -625.689 \\
\hline Akaike Inf. Crit. & $3,241.201$ & $1,256.722$ & $1,257.377$ \\
\hline
\end{tabular}

We should mention that the subjective cost measure is based on an additional survey. Workers were reinvited for a follow-up survey, but clearly there was some attrition, which explains the smaller number of participants. Also, the sample of workers participating in the additional survey are non-representative of our overall sample, e.g., volunteering rates among survey takers was significantly higher compared to those not participating. This auxiliary result should therefore be treated with caution.

\subsection{Confirming the Robustness of the Results}

None of our main results related to group size gives support to our pre-registered hypotheses. This raises the question whether the null-effects with regard to the mean group size and population uncertainty are robust. In this section, we rule out several possible explanations. The general empirical strategy of this section is a two-step argument. First, we show that randomization into treatments worked. This can be seen in Figure 5 , where we plot the average values for different control variables by treatment. Second, we show that some variables do in 
fact predict a main effect of volunteering, but almost none of them substantially interact with the treatments. In fact, of all the 189 treatment and interaction effects we estimate in this section, 10 are marginally statistically significant and only one at a $5 \%$ level. Importantly, even the significant effects do not show any systematic patterns.

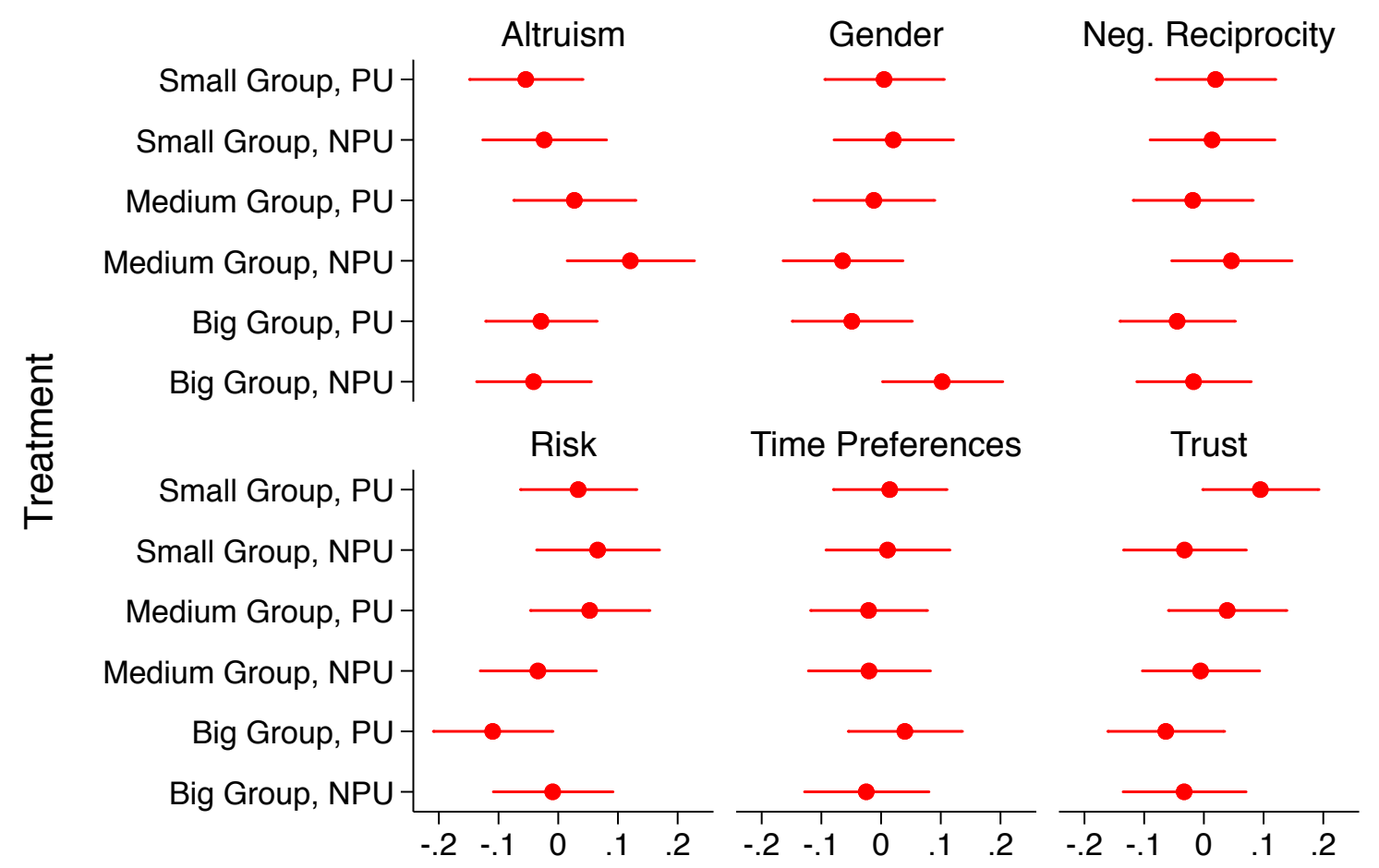

Figure 5: Average values and 95\% confidence intervals of several observables across treatments.

\subsubsection{Prominence of Group Size}

One possible explanation why subjects do not react to the group size in our main treatments might be that they in general do not pay attention to the description of the game and to the group size in particular. For example, it might be the case that they simply overlook the number of players in the team. To minimize this concern first, the instructions are very simple and easy to understand. Second, the size of the team is mentioned two times on the decision screen and prominently directly before making the choice (see Instructions in Appendix D.3). It is still possible that workers who read the instructions don't fully contemplate their decision, the payoff consequences of their actions, and the meaning of the team size for their potential 
payoffs. We note that workers spend more time on the decision screen in the main treatments than in the baseline treatments (Mean VOD $=53.08$ seconds, Mean BAseline $(\mathrm{N}=1)=$ 42.46 seconds, Mann-Whitney U statistic $=306270.5$, p-value $<0.001){ }^{17}$ This suggests that workers indeed take the strategic situation into account.

Additionally, Table C.5 in the Appendix tests for differences in the volunteering rates dependent on the time workers spend on the instructions. If workers pay less attention to the instructions and thus to the group size or the potential for free-riding, we should observe lower volunteering rates for workers who spend more time on the decision page. In contrast, we find a positive effect of the decision time in seconds on volunteering behavior. One explanation for this might be that a longer reading time correlates with other prosocial traits like a sense of duty. Importantly, independently of the precise explanation, we find no interaction between the time spent on the decision screen and group size on volunteering behavior. The differences in decision times thus do not explain our null-findings.

\subsubsection{Workplace-related Reputational Concerns}

One might further argue that many participants volunteered because of reputational concerns. Even though we explicitly pointed out that the volunteering choice has no effect on their reputation, they could have been concerned that they might receive a negative rating on the platform. These concerns should be most pronounced for those workers who have frequently worked on the site in the past, and by implication also expect so in the future. We therefore asked participants how often they had worked on the platform before to construct our REPUTATION score and found no statistically significant differences between treatments $(\mathrm{F}(5,1666)=.74,, \mathrm{p}=.59$, see Figure 5). We do not find a statistically significant effect of REPUTATION on volunteering in a linear probability model with robust standard errors (see Table C.6 in the Appendix). Furthermore, we do not find systematic interaction effects of REPUTATION with our treatment variables. This means that the null-effects are robust to reputational concerns.

\footnotetext{
${ }^{17}$ For the analysis of the attention time, we restrict the sample to observations with values between the 98 th and the 2 th percentile. Including those outliers does not alter the results substantially.
} 


\subsubsection{Economic Preferences}

One might also expect differences in risk-preferences, altruism, or "economic preferences" to explain our results more generally. As explained above, we therefore collected several measures of economic preferences based on the survey measure by Falk et al. (2016), including trust, time preferences, negative reciprocity, and altruism, plus an additional measure of efficiency concerns closely linked to the Volunteer's Dilemma (see Section D.4 in the Appendix for the exact wording of the questions). Also here, most variables are fairly balanced across treatments (see Figure 5). While there are some differences in risk preferences $(\mathrm{F}(5,1725)=2.33), \mathrm{p}=.04)$ and trust $(\mathrm{F}(5,1725)=2.01), \mathrm{p}=.07)$, the other indicators are statistically insignificant $(\mathrm{F}$ test p-values between 0.22 and 0.91). We find positive main effects for time preferences, negative reciprocity, altruism, and efficiency concerns. Importantly, the two factors risk and generalized trust preferences, where randomization was imperfect, seem to play a negligible role for volunteering and are both statistically insignificant at any conventional level. (see Tables C.8 C.13 in the Appendix). Importantly, there is again no significant interaction effect between treatments on any of the preference measures, confirming the robustness of our finding.

\subsubsection{Gender Differences in Volunteering}

Finally, we find the same pattern as above for gender differences in volunteering. Men and women are fairly balanced across treatments $(\mathrm{F}(5,2303)=1.34, \mathrm{p}=.25)$. Women in general volunteer more often, but also here the insignificant interaction effect with our treatments confirms the robustness of our result (see Table C.7 in the Appendix).

\section{Discussion and Concluding Remarks}

In this paper, we study volunteering at the workplace. We report the results of an online field experiment with close to 2,800 workers conducted on an online labor market. In our experiment, our workers first individually worked on a standard classification task, and were later asked to volunteer in a similar task to secure a bonus for all workers of their team. In a total of 8 treatments, we vary the group size, and whether the group size is certain or uncertain. 
While volunteering in work environments is now widespread, and the adaptation is championed by the industry, economic analysis and empirical results suggest that two factors might impede volunteering. First, the incentives create a coordination problem, and second, workers prefer others to do the work leading to a situation similar to the Volunteer's Dilemma. In particular, our game-theoretical model predicts a higher diffusion of responsibility, i.e., lower volunteering rates, in larger groups.

In our theoretical analysis, we extend the theoretical literature on the Volunteer's Dilemma by combining population uncertainty and incomplete information about the costs of other workers. Our theoretical results show that population uncertainty should increase cooperation but the diffusion of responsibility effect prevails.

In stark contrast to our pre-registered theoretical predictions, we neither find an effect of group size nor of population uncertainty on volunteering behavior. On average, about $54 \%$ of workers choose to volunteer across all our main treatments. This null-effect is surprisingly robust. We control for multiple factors that could potentially influence our results. While we find, for instance, that women volunteer more, none of these factors interact with our treatment manipulation. Further measures also show no clear pattern and our treatments are in general balanced given a large number of observables.

Our control treatments help rule out several explanations of our findings. First, workers do react to the strategic situation since they volunteer less than under individual payment. Second, for most workers the incentives seemed to matter: volunteering rates are considerably lower when we do not pay our workers for the additional coding. Also, reassuringly, those workers with lower subjective costs are more likely to volunteer.

The key puzzle is thus why workers react to the volunteering incentives by reducing volunteering rates compared to a situation with individual payments, but at the same time do not react to changes in the group size or population uncertainty although that information was overly salient. Since our study was designed to test theoretical predictions in a field setting, but not to explain a null effect, we are left speculating. A simple explanation would be that the task was too easy or even pleasant. However, while a significant share of workers is willing to work on the task without any payment, as in our UNINCENTIVIZED treatment, this share is considerably lower than in the main treatments. 
A potential explanation that would be in line with our result is that there might be different fixed worker types. Especially in a work environment, it is conceivable that some workers are simply intrinsically motivated to provide good work, independently of monetary or other incentives. The volunteers in our UnINCENTIVIZED treatment would provide an estimate for this share of approximately $27 \%$. There might then be an additional "freeloader" type, i.e., workers who react as soon as an opportunity presents itself to get away without any work. The difference in the share of volunteers in the INCENTIVIZED treatment compared to the main treatments $(68 \%-54 \%=) 14 \%$ would then be an indicator for the prevalence of this type. This would leave the remaining $27 \%$ (54\%-27\% in UninCEnTIVIZED), which one could call dutiful workers who simply work on a task when asked to do so. This interpretation would require these worker types to be stable, and their actions non-strategic, i.e., they do not react to the group size or to the presence of the types of the other workers.

Recent work shows that in situations with dispersed costs and concentrated benefits a considerable amount of decision makers are insensitive to the group size (Schumacher et al. 2017). That is, they ignore potential overall negative welfare effects as long as these costs are sufficiently dispersed. While in the Volunteer's Dilemma benefits are not concentrated, it is still a situation of dispersed costs among volunteers which could lead to a considerable amount of workers who do not take the group size into account. In addition, while work on the Volunteer's Dilemma in more traditional non-field settings show a diffusion of responsibility effect the effect is much smaller, and volunteering rates are in general much higher as predicted (Kopányi-Peuker 2019, Goeree et al. 2017).

Another explanation for our results might be a change in beliefs about other workers' actions due to the treatment. While we did not elicit beliefs (in order to keep the setting natural), one would require the treatment, i.e., the number of players, to influences beliefs. Also, the high volunteering rates are only in line with very pessimistic beliefs. Furthermore, to explain our null effect on the group size, one would require a much more pessimistic belief in large groups than in small groups. In other words, subjects would have to drastically overestimate their own criticality in providing the benefit. However, Hillenbrand and Winter (2018) show that in a Volunteer's dilemma subjects who perceive themselves as more critical actually contribute less suggesting a form of conditional cooperation. In the end, further studies are needed to 
understand better what drives volunteering behavior in the workplace and whether beliefs are correct in expectation.

For organizations that only care about finding at least one volunteer, i.e., who only care about the production of the good, our results are good news. Contrary to what theory or intuition would suggest, giving workers the freedom to self-organize does not hurt commitment. This is true even without oversight and without any negative consequences like the loss of the job or similar ways to punish non-volunteers, which would be a factor in more traditional work environments. Our findings might thus relate to high volunteering rates in other contexts, such as writing open source code or Wikipedia articles, even though the numbers of potential volunteers are sometimes very large.

On the other hand, our results could also point to negative welfare effects, since the very high level of volunteering might be wasteful and thus inefficient. Indeed, these inefficiencies are discussed in open source software development (McConnell 1999, Kenwood 2001). However, while in an optimized pure work environment one would simply stop the process as soon as one volunteer is found, our design allows us to detect the share of "potential volunteers".

Finally, our results shed critical light on the transferability of theoretical and empirical results in, say, a social setting to a seemingly similar environment like a work setting. 


\section{References}

Álvarez-Benjumea, Amalia, "Uncovering Hidden Opinions: The Contagion of Anti-Immigrant Views," MaxPlanck Research Paper Series, 062019.

_ and Fabian Winter, "Normative Change and Culture of Hate: An Experiment in Online Environments," European Sociological Review, 03 2018, 34 (3), 223-237.

and __ , "The Breakdown of Anti-Racist Norms: A Natural Experiment on Normative Uncertainty after Terrorist Attacks," Max Planck Research Paper Series, 062019.

Au, Wing Tung, Xiao-Ping Chen, and S.S. Komorita, "A probabilistic model of criticality in a sequential public good dilemma," Organizational Behavior and Human Decision Processes, 1998, 75 (3), 274-293.

Babcock, Linda, Maria P Recalde, Lise Vesterlund, and Laurie Weingart, "Gender differences in accepting and receiving requests for tasks with low promotability," American Economic Review, 2017, 107 (3), 714-47.

Barron, Greg and Eldad Yechiam, "Private e-mail requests and the diffusion of responsibility," Computers in Human Behavior, 2002, 18 (5), 507-520.

Boosey, Luke, Philip Brookins, and Dmitry Ryvkin, "Contests with group size uncertainty: Experimental evidence," Games and Economic Behavior, 2017, 105, 212-229.

Borchert, Kathrin, Matthias Hirth, Michael Kummer, Ulrich Laitenberger, Olga Slivko, and Steffen Viete, "Unemployment and online labor," ZEW Discussion Papers, 2018, No. 18-023.

Chen, Daniel L, Martin Schonger, and Chris Wickens, "oTree - An open-source platform for laboratory, online, and field experiments," Journal of Behavioral and Experimental Finance, 2016, 9, 88-97.

Darley, John M and Bibb Latané, "Bystander intervention in emergencies: Diffusion of responsibility.," Journal of personality and social psychology, 1968, 8 ((4, Pt.1)), 377-383.

Diekmann, Andreas, "Volunteer's dilemma," Journal of conflict resolution, 1985, 29 (4), 605-610.

_ _ , "Volunteer's Dilemma. A Social Trap without a Dominant Strategy and Some Empirical Results," in "Paradoxical Effects of Social Behavior," Springer, 1986, pp. 187-197.

, "Cooperation in an asymmetric Volunteer's dilemma game theory and experimental evidence," International Journal of Game Theory, 1993, 22 (1), 75-85.

Difallah, Djellel Eddine, Michele Catasta, Gianluca Demartini, Panagiotis G Ipeirotis, and Philippe Cudré-Mauroux, "The dynamics of micro-task crowdsourcing: The case of 
Amazon MTurk," in "Proceedings of the 24th international conference on world wide web" International World Wide Web Conferences Steering Committee 2015, pp. 238-247.

Falk, Armin, Anke Becker, Thomas Dohmen, David Huffman, and Uwe Sunde, "The Preference Survey Module: A Validated Instrument for Measuring Risk, Time, and Social Preferences," IZA Discussion Paper, 2016, No. 9674.

Farrell, Diana and Fiona Greig, "The online platform economy: Has growth peaked?," Technical Report, JP Morgan Chase Institute 2017.

Franzen, Axel, "Group size and one-shot collective action," Rationality and Society, 1995, 7 (2), 183-200.

Goeree, Jacob K., Charles A. Holt, and Angela M. Smith, "An experimental examination of the volunteer's dilemma," Games and Economic Behavior, 2017, 102, 303-315.

Harstad, Ronald M, John H Kagel, and Dan Levin, "Equilibrium bid functions for auctions with an uncertain number of bidders," Economics Letters, 1990, 33 (1), 35-40.

Healy, Andrew J and Jennifer G Pate, "Cost asymmetry and incomplete information in a volunteer's dilemma experiment," Social Choice and Welfare, 2018, pp. 1-27.

Hillenbrand, Adrian and Fabian Winter, "Volunteering under population uncertainty," Games and Economic Behavior, 2018, 109, 65-81.

Hoda, Rashina, Norsaremah Salleh, and John Grundy, "The rise and evolution of agile software development," IEEE Software, 2018, 35 (5), 58-63.

Ioannou, Christos A and Miltiadis Makris, "An experimental study of uncertainty in coordination games," International Economic Review, 2017, Early View.

Jain, Ayush, Akash Das Sarma, Aditya Parameswaran, and Jennifer Widom, "Understanding workers, developing effective tasks, and enhancing marketplace dynamics: a study of a large crowdsourcing marketplace," Proceedings of the VLDB Endowment, 2017, 10 (7), 829-840.

Johnson, Justin Pappas, "Open source software: Private provision of a public good," Journal of Economics \& Management Strategy, 2002, 11 (4), 637-662.

Kenwood, Carolyn A, "A business case study of open source software," Technical Report, MITRE CORP BEDFORD MA 2001.

Kim, Jae Wook and J. Keith Murnighan, "The effects of connectedness and self interest in the organizational volunteer dilemma," International Journal of Conflict Management, 1997, 8 (1), $32-51$.

Kopányi-Peuker, Anita, "Yes, I'll do it: A large-scale experiment on the volunteer's dilemma," Journal of Behavioral and Experimental Economics, 2019, 80, $211-218$. 
Latané, Bibb and Steve Nida, "Ten years of research on group size and helping.," Psychological bulletin, 1981, 89 (2), 308-324.

Lee, Seungjoon, Dave Levin, Vijay Gopalakrishnan, and Bobby Bhattacharjee, "Backbone construction in selfish wireless networks," in "SIGMETRICS Performance Evaluation Review," Vol. 35 ACM 2007, pp. 121-132.

Lim, Wooyoung and Alexander Matros, "Contests with a stochastic number of players," Games and Economic Behavior, 2009, 67 (2), 584-597.

Makris, Miltiadis, "Complementarities and macroeconomics: Poisson games," Games and Economic Behavior, 2008, 62 (1), 180-189.

McConnell, Steve, "Open-source methodology: Ready for prime time," IEEE software, 1999, 16 (4), $6-8$.

Murnighan, J. Keith, Jae Wook Kim, and A. Richard Metzger, "The Volunteer Dilemma," Administrative Science Quarterly, 1993, 38 (4), 515-538.

Myerson, Roger B, "Population uncertainty and Poisson games," International Journal of Game Theory, 1998, 27 (3), 375-392.

__ , "Large Poisson games," Journal of Economic Theory, 2000, 94 (1), 7-45.

Nunez, Matias, "Condorcet consistency of approval voting: a counter example in large Poisson games," Journal of Theoretical Politics, 2010, 22 (1), 64-84.

Peña, Jorge and Georg Nöldeke, "Variability in group size and the evolution of collective action," Journal of Theoretical Biology, 2016, 389, 72-82.

Przepiorka, Wojtek and Joël Berger, "The sanctioning dilemma: a quasi-experiment on social norm enforcement in the train," European Sociological Review, 2016, 32 (3), 439-451.

Ritzberger, Klaus, "Price competition with population uncertainty," Mathematical Social Sciences, $2009,58(2), 145-157$.

Schumacher, Heiner, Iris Kesternich, Michael Kosfeld, and Joachim Winter, "One, two, many - Insensitivity to group size in games with concentrated benefits and dispersed costs," The Review of Economic Studies, 2017, 84 (3), 1346-1377.

Weesie, Jeroen, "Incomplete information and timing in the volunteer's dilemma: A comparison of four models," Journal of Conflict Resolution, 1994, 38 (3), 557-585.

Winter, Fabian and Axel Franzen, "Diffusion of Responsibility in Norm Enforcement," in Ben Jann and Wojtek Przepiorka, eds., Social dilemmas, institutions, and the evolution of cooperation, Berlin: de Gruyter, 2017, p. 303.

Zhang, Xiaoquan Michael and Feng Zhu, "Group size and incentives to contribute: A natural experiment at Chinese Wikipedia," American Economic Review, 2011, 101 (4), 1601-15. 


\section{A Proofs}

Proof of Proposition 1: Existence of the Equilibrium: Assume players play V (Volunteer) and D (Defect) in pure strategies. Thus, for player $i$ it must be the case that $E U_{i}(V) \geq E U_{i}(D)$ or vice versa.

Hence, we have

$$
\begin{gathered}
E U_{i}(V) \geq E U_{i}(D) \\
b_{i}-c_{i} \geq b_{i} P\left(X_{-i}>0\right) \\
b_{i}-c_{i} \geq b_{i}\left(1-P\left(X_{-i}=0\right)\right. \\
\frac{c_{i}}{b_{i}} \leq P\left(X_{-i}=0\right) \\
\gamma_{i} \leq P\left(X_{-i}=0\right)
\end{gathered}
$$

Note that for player $i$ the strategy $\pi_{i}$ is then:

$$
a_{i}=\left\{\begin{array}{l}
\mathrm{V} \text { if } \gamma_{i} \leq P\left(X_{-i}=0\right) \\
\mathrm{D} \text { if } \gamma_{i}>P\left(X_{-i}=0\right)
\end{array}\right.
$$

Note that there exists a type $\tilde{\gamma}_{h}$, which is indifferent between volunteering and defection.

Note that for this indifferent type $\tilde{\gamma}_{h}$ we have $\tilde{\gamma}_{h}=P\left(X_{-i}=0\right)$ and that players with $\gamma_{i}>\tilde{\gamma}_{h}$ will not volunteer. The probability for some player $i$ to be above the threshold $P\left(\gamma_{i}>\tilde{\gamma}_{h}\right)$ is equal to $1-F\left(\tilde{\gamma}_{h}\right)$. Thus, we have

$$
P\left(X_{-i}=0\right)=\sum_{n \in \tilde{N}} h(n)\left(1-F\left(\tilde{\gamma}_{h}\right)\right)^{n-1}
$$

Consider now the indifferent type and note that for him

$$
\begin{gathered}
\tilde{\gamma}_{h}=P\left(X_{-i}=0\right) \\
\Leftrightarrow \tilde{\gamma}_{h}=\sum_{n \in \tilde{N}} h(n)\left(1-F\left(\tilde{\gamma}_{h}\right)\right)^{n-1}
\end{gathered}
$$


holds with $\tilde{\gamma}_{h}$ being the solution to the fixed point condition. This solution will depend on $F(\cdot)$ and $h$. Given the strategy in (2)

$$
a_{i}^{*}=\left\{\begin{array}{l}
\mathrm{V} \text { if } \gamma_{i} \leq \tilde{\gamma}_{h} \\
\mathrm{D} \text { if } \gamma_{i}>\tilde{\gamma}_{h}
\end{array}\right.
$$

describes the strategy of player $i$ in equilibrium. Note that $P\left(\gamma_{i}=\tilde{\gamma}_{h}\right)=0$ as $F(\cdot)$ is atomless. There will never be a player $i$ with a cost-benefit ratio, which is exactly equal to the threshold. Thus, we can neglect the case of $\gamma_{i}=\tilde{\gamma}_{h}{ }^{18}$ This proves that there exists a type-specific pure strategy Nash Equilibrium, which is described by the equilibrium threshold $\tilde{\gamma}_{h}$.

\section{Uniqueness of the solution $\tilde{\gamma}_{h}$ :}

The right-hand side (RHS) of Equation $4, P\left(X_{-i}=0\right)=\sum_{n \in \tilde{N}} h(n)\left(1-F\left(\tilde{\gamma}_{h}\right)\right)^{n-1}$ is decreasing in $\tilde{\gamma}_{h}$ and strictly decreasing for $\tilde{\gamma}_{h} \in[\underline{\omega}, \bar{\omega}]$. The left-hand side (LHS) of Equation 4 is strictly increasing in $\tilde{\gamma}_{h}$. For $\tilde{\gamma}_{h}=\underline{\omega}<1$, the RHS becomes one, as $F(\underline{\omega})=0$. Similarly, for $\tilde{\gamma}_{h}=\bar{\omega}>0$, the RHS equals to zero as $F(\bar{\omega})=1$. Naturally $P\left(X_{-i}=0\right)$ will be bounded by zero and one, as it is a common probability. Thus, there can only be one solution to the fixed point condition 4 . This proves that $\tilde{\gamma}_{h}$ is unique.

Proof of Proposition 1.3: Consider two discrete probability distributions, $j$ and $k$, which describe the group size in the game, and assume that $j$ first-order stochastically dominates $k$. Note that this implies that the mean group size $\mathrm{N}$ is greater given distribution $j$ compared to $k$. By the definition of first-order stochastic dominance, we have for every strictly increasing function $u(n)$ that $\sum_{n \in \tilde{N}} j(n) u(n)>\sum_{n \in \tilde{N}} k(n) u(n)$. Conversely, we get $\sum_{n \in \tilde{N}} k(n) c(n)>$ $\sum_{n \in \tilde{N}} j(n) c(n)$ for $c(n)=-u(n)$.

Note that $\left(1-F\left(\tilde{\gamma}_{h}\right)\right)^{n-1}$ is strictly decreasing in $n$ given $\tilde{\gamma}_{h} \in(\underline{\omega}, \bar{\omega})$. The latter follows directly from the assumption that $\tilde{N}$ is finite, $\{1\} \cap \tilde{N}=\emptyset$ and $\underline{\omega}<\bar{\omega}$. Thus, setting

\footnotetext{
${ }^{18}$ The existence of a player with a threshold is not required for the threshold to exist.
} 
$c(n):=\left(1-F\left(\tilde{\gamma}_{h}\right)\right)^{n-1}$, we therefore get

$$
\sum_{n \in \tilde{N}} k(n)\left(1-F\left(\tilde{\gamma}_{h}\right)\right)^{n-1}>\sum_{n \in \tilde{N}} j(n)\left(1-F\left(\tilde{\gamma}_{h}\right)\right)^{n-1}
$$

Importantly, Equation 6 holds for any equilibrium threshold $\tilde{\gamma}_{h}$ with any arbitrary discrete probability distribution $h$. This is because $F(\cdot)$ stays unchanged and we only alter the distribution $h$, which then has an influence on the solution $\tilde{\gamma}_{h}$. Given Equality 4 and Inequality 6 , we then have

$$
\tilde{\gamma}_{k}=\sum_{n \in \tilde{N}} k(n)\left(1-F\left(\tilde{\gamma}_{k}\right)\right)^{n-1}>\sum_{n \in \tilde{N}} j(n)\left(1-F\left(\tilde{\gamma}_{k}\right)\right)^{n-1}
$$

and

$$
\sum_{n \in \tilde{N}} k(n)\left(1-F\left(\tilde{\gamma}_{j}\right)\right)^{n-1}>\sum_{n \in \tilde{N}} j(n)\left(1-F\left(\tilde{\gamma}_{j}\right)\right)^{n-1}=\tilde{\gamma}_{j},
$$

where $\tilde{\gamma}_{k}$ and $\tilde{\gamma}_{j}$ denote the equilibrium thresholds for the respective probability distributions of $n$. Lastly, assume by contradiction that $\tilde{\gamma}_{k} \leq \tilde{\gamma}_{j}$. Then we have

$$
\begin{gathered}
\tilde{\gamma}_{k} \leq \tilde{\gamma}_{j} \\
\Leftrightarrow \tilde{\gamma}_{k} \leq \sum_{n \in \tilde{N}} j(n)\left(1-F\left(\tilde{\gamma}_{j}\right)\right)^{n-1} \\
\Leftrightarrow \sum_{n \in \tilde{N}} j(n)\left(1-F\left(\tilde{\gamma}_{k}\right)\right)^{n-1}<\sum_{n \in \tilde{N}} j(n)\left(1-F\left(\tilde{\gamma}_{j}\right)\right)^{n-1}
\end{gathered}
$$


using Equation 4 in the second and Equation 7 in the last step.

However, $\left(1-F\left(\tilde{\gamma}_{h}\right)\right)^{n-1}$ is (weakly) decreasing in $\tilde{\gamma}_{h}$ for $\forall n \in \tilde{N}$. Hence, $\tilde{\gamma}_{k} \leq \tilde{\gamma}_{j}$ implies that

$$
\begin{gathered}
\quad\left(1-F\left(\tilde{\gamma}_{k}\right)\right)^{n-1} \geq\left(1-F\left(\tilde{\gamma}_{j}\right)\right)^{n-1} \forall n \in \tilde{N} \\
\Leftrightarrow j(n)\left(1-F\left(\tilde{\gamma}_{k}\right)\right)^{n-1} \geq j(n)\left(1-F\left(\tilde{\gamma}_{j}\right)\right)^{n-1} \forall n \in \tilde{N} \\
\Leftrightarrow \sum_{n \in \tilde{N}} j(n)\left(1-F\left(\tilde{\gamma}_{k}\right)\right)^{n-1} \geq \sum_{n \in \tilde{N}} j(n)\left(1-F\left(\tilde{\gamma}_{j}\right)\right)^{n-1},
\end{gathered}
$$

as $j(n) \geq 0 \forall n$ and $\left(1-F\left(\tilde{\gamma}_{j, k}\right)\right)^{n-1}>0 \forall n$ by the observation that $\tilde{\gamma}_{j, k} \in(\underline{\omega}, \bar{\omega})$. This yields the desired contradiction if we compare Equation 9 and Equation 10 and proves that $\tilde{\gamma}_{k}>\tilde{\gamma}_{j}$.

We are interested in the influence the population uncertainty has on this equilibrium of the game. Specifically, we want to compare the threshold $\tilde{\gamma}_{h}$ given different degrees of population uncertainty. We define population uncertainty in the notion of Hillenbrand and Winter (2018).

Definition 1. Assume that $g$ and $z$ are two discrete probability distributions of the number of players $n$ in the game. Let $z$ be a mean-preserving spread of $g$. Then, $z$ has a higher degree of population uncertainty than $g$.

In the following, we compare the equilibrium under these two distributions $g$ and $z$, which we defined in Definition 1 to see which influence the change in population uncertainty has on volunteering behavior. Both distributions have the properties imposed on $h$.

\section{Proof of Proposition 2:}

Let $h$ be some arbitrary discrete probability distribution describing the population size. Denote $\tilde{\gamma}_{h}$ as the equilibrium threshold, as in Proposition 11. Note that given $\tilde{\gamma}_{h} \in(\underline{\omega}, \bar{\omega})$ we have $\left(1-F\left(\tilde{\gamma}_{h}\right)\right) \in(0,1)$ for any equilibrium threshold. Hence, for any given distribution $h$ the function $\left(1-F\left(\tilde{\gamma}_{h}\right)\right)^{n-1}$ will be strictly decreasing and strictly convex in $n \geq 2$ for a fixed equilibrium threshold $\tilde{\gamma}_{h}$.

Assume that $z$ and $g$ are two arbitrary discrete probability distributions of $n$ and that $z$ is a mean-preserving spread of $g\left(z_{m p s} g\right)$ as defined in Definition 1. Note that this implies that $g$ second-order stochastically dominates $z$. Thus, for every strictly increasing and strictly 
concave function $u(n)$, it must hold that $\sum_{n \in \tilde{N}} z(n) u(n)<\sum_{n \in \tilde{N}} g(n) u(n)$. Conversely, we get $\sum_{n \in \tilde{N}} z(n) c(n)>\sum_{n \in \tilde{N}} g(n) c(n)$ for any strictly convex function $c(n)=-u(n)$. Setting $c(n):=\left(1-F\left(\tilde{\gamma}_{h}\right)\right)^{n-1}$, we therefore get

$$
\sum_{n \in \tilde{N}} z(n)\left(1-F\left(\tilde{\gamma}_{h}\right)\right)^{n-1}>\sum_{n \in \tilde{N}} g(n)\left(1-F\left(\tilde{\gamma}_{h}\right)\right)^{n-1}
$$

By following an analogous approach as in the proof of Proposition 1.3, it then follows that $\tilde{\gamma}_{z}>\tilde{\gamma}_{g}$.

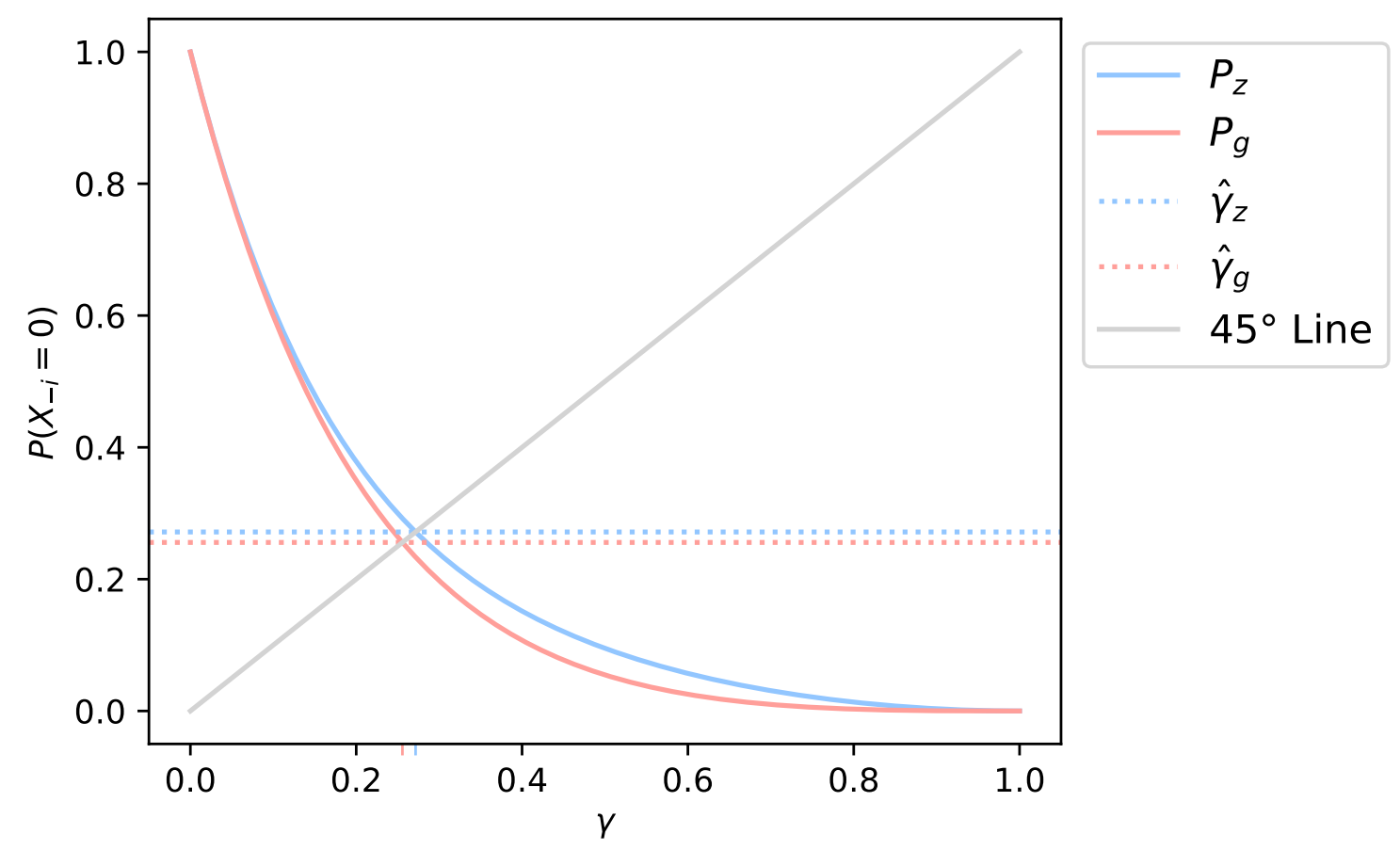

Figure A.1: The probability that no other player volunteers $P\left(X_{-i}=0\right)$ as a function of $\gamma$ for some arbitrary distributions $g$ and $z$ of $n$ with $z_{m p s} g$. We assume that $\gamma \sim U(0,1)$.

Figure A.1 helps to visualize this proof. The probability that no other player volunteers $P\left(X_{-i}=0\right):=P_{z, g}$ is decreasing in $\gamma$. Furthermore, the equilibrium threshold for $g$ and $z$ is defined by the intersection of the $45^{\circ}$ line and the function $P\left(X_{-i}=0\right)$, as this is the solution to the fixed point condition 4 . As $g$ second-order stochastic dominates $z$ and $(1-F(\tilde{\gamma}))^{n-1}$ 
is decreasing and convex in $n, P_{z}(\gamma)>P_{g}(\gamma)$ for the relevant domain of $\gamma{ }^{19}$ Now, given the solution will be defined by the intersection of $P_{z, g}$ with the $45^{\circ}$ line, it follows that $\tilde{\gamma}_{z}>\tilde{\gamma}_{g}$ as shown in Figure A.1.

\footnotetext{
${ }^{19}$ As shown in the derivation of Equation 11 this will be a strict inequality for any equilibrium threshold, but, for instance, $P_{z}(\gamma)=P_{g}(\gamma)$ for $\gamma=0$.
} 


\section{B Additional Figures and Tables}

Table B.1: Equilibrium predictions for two different cost-benefit distributions.

\begin{tabular}{cccc}
\hline \multirow{2}{*}{ Mean Group Size } & \multirow{2}{*}{ Distribution $\mathscr{F}$} & \multicolumn{2}{c}{ Predicted Volunteering rate } \\
& $\mathrm{PU}\left(s=\frac{N}{3}\right)$ & $\mathrm{NPU}(s=0)$ \\
\hline \multirow{2}{*}{ Small Group $(N=3)$} & Uniform $(0,1)$ & 0.3962 & 0.3820 \\
& $\operatorname{Beta}(2,4)$ & 0.3062 & 0.2935 \\
\hline \multirow{2}{*}{ Medium Group $(N=30)$} & $\operatorname{Uniform}(0,1)$ & 0.0857 & 0.0825 \\
& $\operatorname{Beta}(2,4)$ & 0.0994 & 0.0971 \\
\hline \multirow{2}{*}{ Big Group $(N=300)$} & Uniform $(0,1)$ & 0.0151 & 0.0141 \\
& $\operatorname{Beta}(2,4)$ & 0.0357 & 0.0346 \\
\hline
\end{tabular}

Note: The predicted volunteering rates for the Volunteer's Dilemma with Incomplete Information with Population Uncertainty (PU) and with no Population Uncertainty (NPU) are shown. The spread of the population distribution is denoted by $s$ and $N$ denotes the mean group size. The predictions are given for two arbitrary cost-benefit ratio distribution $\gamma \sim \mathscr{F}$.

Table B.2: The mean of different socioeconomic and demographic variables for all treatments

\begin{tabular}{lc}
\multicolumn{2}{c}{ Region \& City Size } \\
\hline \hline Statistic & Mean \\
\hline West Germany & 0.819 \\
City size: Less 50k & 0.395 \\
City size: 50k-200k & 0.198 \\
City size: 200k-500k & 0.127 \\
City size: 500k-1500k & 0.134 \\
City size: More 1500k & 0.146 \\
\hline
\end{tabular}

\begin{tabular}{lc}
\multicolumn{2}{c}{ Educational Level } \\
\hline \hline Statistic & Mean \\
\hline School not finished & 0.032 \\
High School & 0.340 \\
Apprenticeship & 0.286 \\
Bachelor & 0.173 \\
Master & 0.170 \\
\hline
\end{tabular}

\section{Employment Status}

\begin{tabular}{ll}
\hline \hline Variable & Mean \\
\hline Student & 0.239 \\
Not employed & 0.019 \\
Searching & 0.043 \\
Employed & 0.526 \\
Self employed & 0.118 \\
Retired & 0.024 \\
Other & 0.031 \\
\hline
\end{tabular}

Age \& Gender

\begin{tabular}{ll}
\hline \hline Statistic & Mean \\
\hline Woman & 0.478 \\
Age: $18-25$ & 0.293 \\
Age: $26-35$ & 0.369 \\
Age: $36-45$ & 0.178 \\
Age: $45-55$ & 0.107 \\
Age: $55+$ & 0.054 \\
\hline
\end{tabular}


Table B.3: The Volunteering choice explained by all treatment dummies in a LPM with robust standard errors

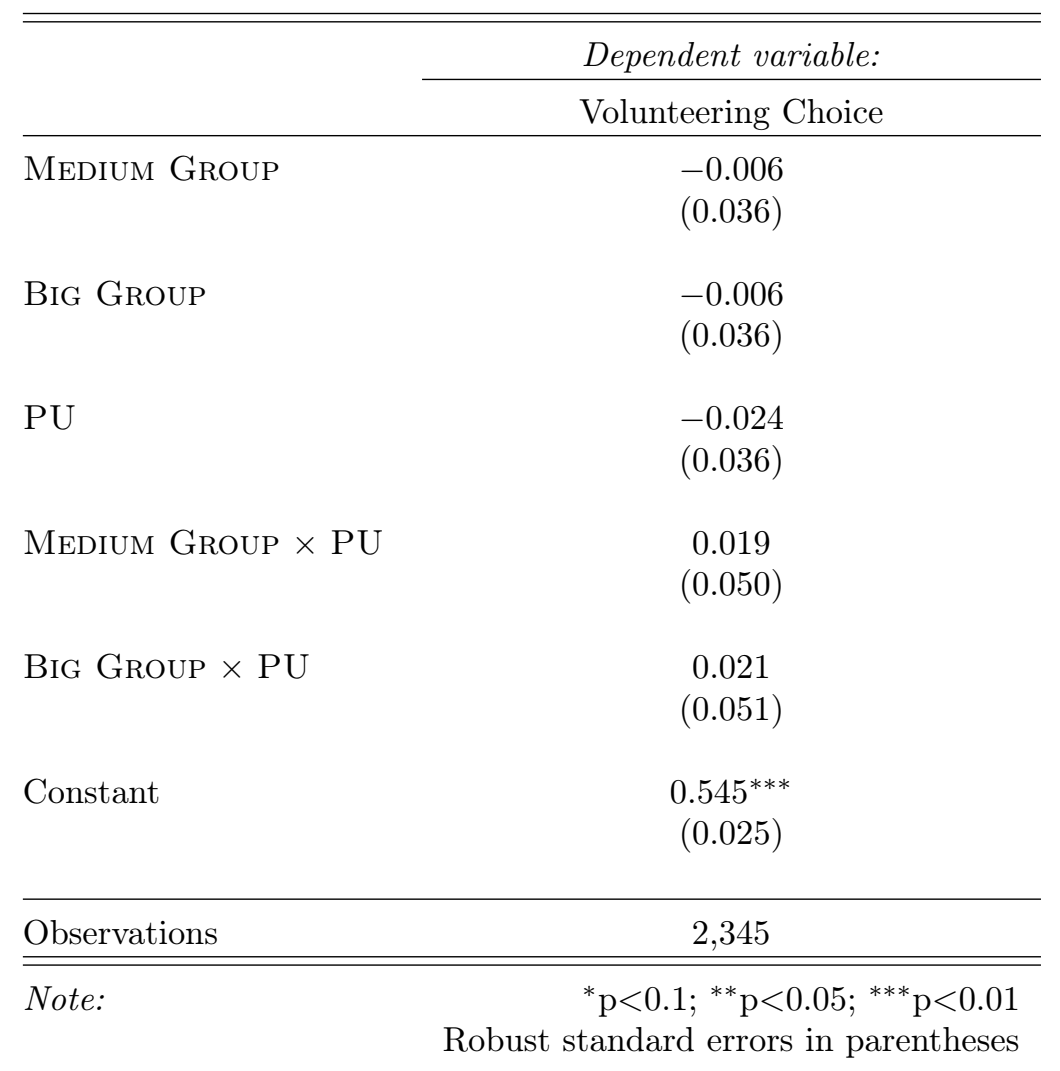


Table B.4: Estimated average marginal effects for the main cost measures on volunteering for model specification (3) from Table 3 in the main text.

\begin{tabular}{lrrrrrr}
\hline & AME & SE & $z$ & $p$ & lower & upper \\
\hline Time & 0.02 & 0.02 & 1.07 & 0.29 & -0.02 & 0.06 \\
Cost IndEx & -0.05 & 0.02 & -3.34 & 0.00 & -0.08 & -0.02 \\
\hline
\end{tabular}




\section{Regression Tables}

\section{C.1 Preregistered Analysis}

Table C.1: Logistic Regression estimating the probability of volunteering

\begin{tabular}{|c|c|c|c|}
\hline & \multicolumn{3}{|c|}{ Dependent variable: } \\
\hline & \multicolumn{3}{|c|}{ Volunteering Choice } \\
\hline & (1) & $(2)$ & $(3)$ \\
\hline Medium Group & $\begin{array}{c}0.014 \\
(0.101)\end{array}$ & $\begin{array}{c}0.014 \\
(0.101)\end{array}$ & $\begin{array}{l}-0.024 \\
(0.143)\end{array}$ \\
\hline Big Group & $\begin{array}{c}0.016 \\
(0.101)\end{array}$ & $\begin{array}{c}0.017 \\
(0.101)\end{array}$ & $\begin{array}{l}-0.025 \\
(0.144)\end{array}$ \\
\hline $\mathrm{PU}$ & & $\begin{array}{l}-0.043 \\
(0.083)\end{array}$ & $\begin{array}{l}-0.096 \\
(0.143)\end{array}$ \\
\hline Medium Group $\times$ PU & & & $\begin{array}{c}0.077 \\
(0.202)\end{array}$ \\
\hline Big Group $\times$ PU & & & $\begin{array}{c}0.083 \\
(0.203)\end{array}$ \\
\hline Constant & $\begin{array}{l}0.134^{*} \\
(0.071)\end{array}$ & $\begin{array}{l}0.156^{*} \\
(0.082)\end{array}$ & $\begin{array}{l}0.182^{*} \\
(0.101)\end{array}$ \\
\hline Observations & 2,345 & 2,345 & 2,345 \\
\hline Akaike Inf. Crit. & $3,244.639$ & $3,246.366$ & $3,250.157$ \\
\hline
\end{tabular}


Table C.2: Estimated average marginal effects for the main treatment variable for model specification (3)

\begin{tabular}{lrrrrrrr}
\hline & PoP. UNC. & AME & SE & z & p & lower & upper \\
\hline Big Group & NPU & -0.02 & 0.14 & -0.17 & 0.86 & -0.31 & 0.26 \\
Big Group & PU & 0.06 & 0.14 & 0.40 & 0.69 & -0.22 & 0.34 \\
MEDIUM Group & NPU & -0.02 & 0.14 & -0.17 & 0.87 & -0.30 & 0.26 \\
MEDIUM Group & PU & 0.05 & 0.14 & 0.37 & 0.71 & -0.23 & 0.33 \\
\hline
\end{tabular}

Table C.3: Logit Regression to estimate the volunteering choice as a function of different pre-registered cost measures

\begin{tabular}{|c|c|c|c|}
\hline & \multicolumn{3}{|c|}{ Dependent variable: } \\
\hline & \multicolumn{3}{|c|}{ Volunteering Choice } \\
\hline & $(1)$ & $(2)$ & (3) \\
\hline Time & $\begin{array}{l}-0.002 \\
(0.002)\end{array}$ & $\begin{array}{c}-0.002 \\
(0.002)\end{array}$ & $\begin{array}{l}-0.003 \\
(0.003)\end{array}$ \\
\hline TASK EXPERIENCE & & $\begin{array}{l}0.0004 \\
(0.001)\end{array}$ & $\begin{array}{l}-0.001 \\
(0.006)\end{array}$ \\
\hline REPUTATION & & $\begin{array}{c}0.012 \\
(0.010)\end{array}$ & $\begin{array}{c}0.008 \\
(0.017)\end{array}$ \\
\hline REPUTATION $\times$ TASK EXPERIENCE & & & $\begin{array}{c}-0.0002 \\
(0.001)\end{array}$ \\
\hline TASK EXPERIENCE $\times$ Time & & & $\begin{array}{l}0.0003 \\
(0.001)\end{array}$ \\
\hline Reputation $\times$ Time & & & $\begin{array}{l}0.0004 \\
(0.001)\end{array}$ \\
\hline Constant & $\begin{array}{c}0.169^{* * *} \\
(0.047)\end{array}$ & $\begin{array}{c}0.161^{* * *} \\
(0.053)\end{array}$ & $\begin{array}{c}0.172^{* * *} \\
(0.060)\end{array}$ \\
\hline Observations & 2,345 & 2,237 & 2,237 \\
\hline Akaike Inf. Crit. & $3,241.201$ & $3,090.357$ & $3,095.922$ \\
\hline
\end{tabular}


Table C.4: Average marginal effects for model specification (3)

\begin{tabular}{lrrrrrr}
\hline & AME & SE & $\mathrm{z}$ & $\mathrm{p}$ & lower & upper \\
\hline REPUTATION & 0.00 & 0.00 & 1.26 & 0.21 & -0.00 & 0.01 \\
TASK EXPERIENCE & 0.00 & 0.00 & 0.36 & 0.72 & -0.00 & 0.00 \\
TIME & -0.00 & 0.00 & -0.82 & 0.41 & -0.00 & 0.00 \\
\hline
\end{tabular}




\section{C.2 Robustness Checks with Regard to Different Control Variables}

Table C.5: The volunteering choice explained by ATTENTION and all treatment dummies in a linear probability model with robust standard errors

\begin{tabular}{|c|c|c|c|c|}
\hline & \multicolumn{4}{|c|}{ Dependent variable: } \\
\hline & \multicolumn{4}{|c|}{ Volunteering Choice } \\
\hline & $(1)$ & $(2)$ & $(3)$ & $(4)$ \\
\hline Attention & $\begin{array}{l}0.002^{* * *} \\
(0.0004)\end{array}$ & $\begin{array}{c}0.002^{* * *} \\
(0.0004)\end{array}$ & $\begin{array}{c}0.003^{* * *} \\
(0.001)\end{array}$ & $\begin{array}{c}0.004^{* * *} \\
(0.001)\end{array}$ \\
\hline Medium Group & & $\begin{array}{c}0.002 \\
(0.025)\end{array}$ & $\begin{array}{c}0.076 \\
(0.067)\end{array}$ & $\begin{array}{c}0.143 \\
(0.095)\end{array}$ \\
\hline Big Group & & $\begin{array}{c}-0.008 \\
(0.026)\end{array}$ & $\begin{array}{c}0.056 \\
(0.067)\end{array}$ & $\begin{array}{c}0.099 \\
(0.095)\end{array}$ \\
\hline PU & & $\begin{array}{l}-0.019 \\
(0.021)\end{array}$ & $\begin{array}{l}-0.085 \\
(0.058)\end{array}$ & $\begin{array}{c}-0.016 \\
(0.093)\end{array}$ \\
\hline MEDIUM GRoup $\times \mathrm{PU}$ & & & $\begin{array}{c}0.035 \\
(0.051)\end{array}$ & $\begin{array}{c}-0.086 \\
(0.127)\end{array}$ \\
\hline BIG Group $\times$ PU & & & $\begin{array}{c}0.029 \\
(0.051)\end{array}$ & $\begin{array}{c}-0.045 \\
(0.129)\end{array}$ \\
\hline Medium Group $\times$ Attention & & & $\begin{array}{l}-0.002 \\
(0.001)\end{array}$ & $\begin{array}{c}-0.003^{*} \\
(0.002)\end{array}$ \\
\hline Big Group $\times$ Attention & & & $\begin{array}{l}-0.001 \\
(0.001)\end{array}$ & $\begin{array}{l}-0.002 \\
(0.002)\end{array}$ \\
\hline PU $\times$ Attention & & & $\begin{array}{c}0.001 \\
(0.001)\end{array}$ & $\begin{array}{c}-0.001 \\
(0.002)\end{array}$ \\
\hline Medium Group $\times$ PU $\times$ Attention & & & & $\begin{array}{c}0.002 \\
(0.002)\end{array}$ \\
\hline Big Group $\times$ PU $\times$ Attention & & & & $\begin{array}{c}0.001 \\
(0.002)\end{array}$ \\
\hline Constant & $\begin{array}{c}0.416^{* * *} \\
(0.026)\end{array}$ & $\begin{array}{c}0.427^{* * *} \\
(0.031)\end{array}$ & $\begin{array}{c}0.401^{* * *} \\
(0.055)\end{array}$ & $\begin{array}{c}0.360^{* * *} \\
(0.071)\end{array}$ \\
\hline Observations & 2,252 & 2,252 & 2,252 & 2,252 \\
\hline
\end{tabular}


Table C.6: The volunteering choice explained by REPUTATION and all treatment dummies in a linear probability model with robust standard errors

\begin{tabular}{|c|c|c|c|c|}
\hline & \multicolumn{4}{|c|}{ Dependent variable: } \\
\hline & \multicolumn{4}{|c|}{ Volunteering Choice } \\
\hline & $(1)$ & $(2)$ & (3) & $(4)$ \\
\hline REPUTATION & $\begin{array}{c}0.003 \\
(0.002)\end{array}$ & $\begin{array}{c}0.003 \\
(0.002)\end{array}$ & $\begin{array}{c}0.004 \\
(0.004)\end{array}$ & $\begin{array}{c}0.004 \\
(0.005)\end{array}$ \\
\hline MEdium Group & & $\begin{array}{c}0.008 \\
(0.026)\end{array}$ & $\begin{array}{c}0.012 \\
(0.038)\end{array}$ & $\begin{array}{c}0.026 \\
(0.040)\end{array}$ \\
\hline Big Group & & $\begin{array}{l}0.0005 \\
(0.026)\end{array}$ & $\begin{array}{c}0.005 \\
(0.038)\end{array}$ & $\begin{array}{l}-0.010 \\
(0.040)\end{array}$ \\
\hline $\mathrm{PU}$ & & $\begin{array}{l}-0.014 \\
(0.021)\end{array}$ & $\begin{array}{l}-0.049 \\
(0.038)\end{array}$ & $\begin{array}{l}-0.051 \\
(0.041)\end{array}$ \\
\hline MEdium GRoup $\times$ PU & & & $\begin{array}{c}0.035 \\
(0.051)\end{array}$ & $\begin{array}{c}0.010 \\
(0.057)\end{array}$ \\
\hline BIG GROUP $\times$ PU & & & $\begin{array}{c}0.020 \\
(0.052)\end{array}$ & $\begin{array}{c}0.042 \\
(0.057)\end{array}$ \\
\hline Medium Group $\times$ REPUtation & & & $\begin{array}{c}-0.011^{*} \\
(0.006)\end{array}$ & $\begin{array}{c}-0.019^{* *} \\
(0.008)\end{array}$ \\
\hline Big Group $\times$ REPUtation & & & $\begin{array}{l}-0.007 \\
(0.005)\end{array}$ & $\begin{array}{l}0.0005 \\
(0.008)\end{array}$ \\
\hline PU $\times$ REPUTATION & & & $\begin{array}{l}0.008^{*} \\
(0.005)\end{array}$ & $\begin{array}{c}0.009 \\
(0.008)\end{array}$ \\
\hline MEDium GRouP $\times$ PU $\times$ REPUTATION & & & & $\begin{array}{c}0.013 \\
(0.011)\end{array}$ \\
\hline Big Group $\times$ PU $\times$ REPUtATION & & & & $\begin{array}{l}-0.010 \\
(0.011)\end{array}$ \\
\hline Constant & $\begin{array}{c}0.534^{* * *} \\
(0.011)\end{array}$ & $\begin{array}{c}0.538^{* * *} \\
(0.021)\end{array}$ & $\begin{array}{c}0.545^{* * *} \\
(0.027)\end{array}$ & $\begin{array}{c}0.546^{* * *} \\
(0.028)\end{array}$ \\
\hline Observations & 2,246 & 2,246 & 2,246 & 2,246 \\
\hline
\end{tabular}


Table C.7: The volunteering choice explained by WomAn and all treatment dummies in a linear probability model with robust standard errors

\begin{tabular}{|c|c|c|c|c|}
\hline & \multicolumn{4}{|c|}{ Dependent variable: } \\
\hline & \multicolumn{4}{|c|}{ Volunteering Choice } \\
\hline & $(1)$ & $(2)$ & $(3)$ & (4) \\
\hline WOMAN & $\begin{array}{c}0.102^{* * *} \\
(0.021)\end{array}$ & $\begin{array}{c}0.103^{* * *} \\
(0.021)\end{array}$ & $\begin{array}{c}0.126^{* * *} \\
(0.041)\end{array}$ & $\begin{array}{l}0.124^{* *} \\
(0.050)\end{array}$ \\
\hline Medium Group & & $\begin{array}{l}-0.002 \\
(0.025)\end{array}$ & $\begin{array}{l}-0.011 \\
(0.044)\end{array}$ & $\begin{array}{l}-0.034 \\
(0.050)\end{array}$ \\
\hline Big Group & & $\begin{array}{c}-0.0005 \\
(0.025)\end{array}$ & $\begin{array}{c}0.008 \\
(0.043)\end{array}$ & $\begin{array}{c}0.026 \\
(0.049)\end{array}$ \\
\hline $\mathrm{PU}$ & & $\begin{array}{l}-0.012 \\
(0.021)\end{array}$ & $\begin{array}{l}-0.025 \\
(0.041)\end{array}$ & $\begin{array}{l}-0.027 \\
(0.049)\end{array}$ \\
\hline Medium Group $\times$ PU & & & $\begin{array}{c}0.033 \\
(0.051)\end{array}$ & $\begin{array}{c}0.079 \\
(0.071)\end{array}$ \\
\hline BIG Group $\times$ PU & & & $\begin{array}{c}0.021 \\
(0.051)\end{array}$ & $\begin{array}{l}-0.017 \\
(0.070)\end{array}$ \\
\hline MEdium GRoup $\times$ Woman & & & $\begin{array}{l}-0.016 \\
(0.051)\end{array}$ & $\begin{array}{c}0.030 \\
(0.071)\end{array}$ \\
\hline Big Group $\times$ Woman & & & $\begin{array}{l}-0.040 \\
(0.051)\end{array}$ & $\begin{array}{l}-0.082 \\
(0.072)\end{array}$ \\
\hline $\mathrm{PU} \times$ WOMAN & & & $\begin{array}{l}-0.009 \\
(0.041)\end{array}$ & $\begin{array}{l}-0.005 \\
(0.071)\end{array}$ \\
\hline Medium Group $\times$ PU $\times$ Woman & & & & $\begin{array}{l}-0.093 \\
(0.101)\end{array}$ \\
\hline BIG GROUP $\times$ PU $\times$ WOMAN & & & & $\begin{array}{c}0.082 \\
(0.102)\end{array}$ \\
\hline Constant & $\begin{array}{c}0.490^{* * *} \\
(0.014)\end{array}$ & $\begin{array}{c}0.496^{* * *} \\
(0.023)\end{array}$ & $\begin{array}{c}0.494^{* * *} \\
(0.032)\end{array}$ & $\begin{array}{c}0.495^{* * *} \\
(0.035)\end{array}$ \\
\hline Observations & 2,309 & 2,309 & 2,309 & 2,309 \\
\hline
\end{tabular}


Table C.8: The volunteering choice explained by EFFICIENCY and all treatment dummies in a linear probability model with robust standard errors

\begin{tabular}{|c|c|c|c|c|}
\hline & \multicolumn{4}{|c|}{ Dependent variable: } \\
\hline & \multicolumn{4}{|c|}{ Volunteering Choice } \\
\hline & $(1)$ & $(2)$ & $(3)$ & $(4)$ \\
\hline EFFICIENCY & $\begin{array}{c}0.017^{* * *} \\
(0.004)\end{array}$ & $\begin{array}{c}0.017^{* * *} \\
(0.004)\end{array}$ & $\begin{array}{c}0.006 \\
(0.008)\end{array}$ & $\begin{array}{c}0.002 \\
(0.010)\end{array}$ \\
\hline Medium Group & & $\begin{array}{c}0.005 \\
(0.025)\end{array}$ & $\begin{array}{l}-0.077 \\
(0.074)\end{array}$ & $\begin{array}{c}-0.170^{*} \\
(0.097)\end{array}$ \\
\hline Big Group & & $\begin{array}{c}0.007 \\
(0.025)\end{array}$ & $\begin{array}{l}-0.061 \\
(0.073)\end{array}$ & $\begin{array}{l}-0.053 \\
(0.097)\end{array}$ \\
\hline $\mathrm{PU}$ & & $\begin{array}{l}-0.011 \\
(0.021)\end{array}$ & $\begin{array}{l}-0.082 \\
(0.064)\end{array}$ & $\begin{array}{l}-0.138 \\
(0.098)\end{array}$ \\
\hline Medium Group $\times$ PU & & & $\begin{array}{c}0.019 \\
(0.050)\end{array}$ & $\begin{array}{c}0.215 \\
(0.141)\end{array}$ \\
\hline Big Group $\times$ PU & & & $\begin{array}{c}0.027 \\
(0.050)\end{array}$ & $\begin{array}{c}0.016 \\
(0.137)\end{array}$ \\
\hline Medium Group $\times$ EFficiency & & & $\begin{array}{c}0.011 \\
(0.010)\end{array}$ & $\begin{array}{l}0.026^{*} \\
(0.014)\end{array}$ \\
\hline Big Group $\times$ EFFICIENCY & & & $\begin{array}{c}0.009 \\
(0.010)\end{array}$ & $\begin{array}{c}0.007 \\
(0.014)\end{array}$ \\
\hline $\mathrm{PU} \times$ EFFICIENCY & & & $\begin{array}{c}0.009 \\
(0.008)\end{array}$ & $\begin{array}{c}0.018 \\
(0.014)\end{array}$ \\
\hline Medium Group $\times$ PU $\times$ EFficiency & & & & $\begin{array}{l}-0.031 \\
(0.021)\end{array}$ \\
\hline Big Group $\times$ PU $\times$ EFficiency & & & & $\begin{array}{c}0.002 \\
(0.020)\end{array}$ \\
\hline Constant & $\begin{array}{c}0.428^{* * *} \\
(0.028)\end{array}$ & $\begin{array}{c}0.429^{* * *} \\
(0.034)\end{array}$ & $\begin{array}{c}0.506^{* * *} \\
(0.058)\end{array}$ & $\begin{array}{c}0.533^{* * *} \\
(0.068)\end{array}$ \\
\hline Observations & 2,345 & 2,345 & 2,345 & 2,345 \\
\hline
\end{tabular}


Table C.9: The Volunteering choice explained by Altruism and all treatment dummies in a linear probability model with robust standard errors

\begin{tabular}{|c|c|c|c|c|}
\hline & \multicolumn{4}{|c|}{ Dependent variable: } \\
\hline & \multicolumn{4}{|c|}{ Volunteering Choice } \\
\hline & $(1)$ & $(2)$ & $(3)$ & $(4)$ \\
\hline Altruism & $\begin{array}{c}0.0001^{* *} \\
(0.0001)\end{array}$ & $\begin{array}{c}0.0001^{* *} \\
(0.0001)\end{array}$ & $\begin{array}{c}0.00005 \\
(0.0001)\end{array}$ & $\begin{array}{l}0.00005 \\
(0.0001)\end{array}$ \\
\hline Medium Group & & $\begin{array}{c}0.001 \\
(0.025)\end{array}$ & $\begin{array}{l}-0.027 \\
(0.040)\end{array}$ & $\begin{array}{l}-0.019 \\
(0.044)\end{array}$ \\
\hline Big Group & & $\begin{array}{c}0.004 \\
(0.025)\end{array}$ & $\begin{array}{l}-0.001 \\
(0.040)\end{array}$ & $\begin{array}{l}-0.010 \\
(0.044)\end{array}$ \\
\hline PU & & $\begin{array}{l}-0.010 \\
(0.021)\end{array}$ & $\begin{array}{l}-0.032 \\
(0.038)\end{array}$ & $\begin{array}{l}-0.033 \\
(0.043)\end{array}$ \\
\hline Medium GRoup $\times$ PU & & & $\begin{array}{c}0.021 \\
(0.050)\end{array}$ & $\begin{array}{c}0.005 \\
(0.062)\end{array}$ \\
\hline Big Group $\times$ PU & & & $\begin{array}{c}0.020 \\
(0.051)\end{array}$ & $\begin{array}{c}0.039 \\
(0.062)\end{array}$ \\
\hline Medium Group $\times$ Altruism & & & $\begin{array}{c}0.0001 \\
(0.0001)\end{array}$ & $\begin{array}{c}0.0001 \\
(0.0002)\end{array}$ \\
\hline Big Group $\times$ Altruism & & & $\begin{array}{c}-0.00004 \\
(0.0001)\end{array}$ & $\begin{array}{l}0.00003 \\
(0.0002)\end{array}$ \\
\hline $\mathrm{PU} \times$ Altruism & & & $\begin{array}{c}0.0001 \\
(0.0001)\end{array}$ & $\begin{array}{c}0.0001 \\
(0.0002)\end{array}$ \\
\hline Medium Group $\times$ PU $\times$ Altruism & & & & $\begin{array}{c}0.0001 \\
(0.0003)\end{array}$ \\
\hline Big Group $\times$ PU $\times$ Altruism & & & & $\begin{array}{l}-0.0001 \\
(0.0003)\end{array}$ \\
\hline Constant & $\begin{array}{c}0.521^{* * *} \\
(0.013)\end{array}$ & $\begin{array}{c}0.524^{* * *} \\
(0.022)\end{array}$ & $\begin{array}{c}0.539^{* * *} \\
(0.029)\end{array}$ & $\begin{array}{c}0.540^{* * *} \\
(0.030)\end{array}$ \\
\hline Observations & 2,345 & 2,345 & 2,345 & 2,345 \\
\hline
\end{tabular}


Table C.10: The volunteering choice explained by Negative Reciprocity and all treatment dummies in a linear probability model with robust standard errors

\begin{tabular}{|c|c|c|c|c|}
\hline & \multicolumn{4}{|c|}{ Dependent variable: } \\
\hline & \multicolumn{4}{|c|}{ Volunteering Choice } \\
\hline & $(1)$ & $(2)$ & $(3)$ & $(4)$ \\
\hline N. RECIPROCITY & $\begin{array}{c}0.012^{* * *} \\
(0.004)\end{array}$ & $\begin{array}{c}0.012^{* * *} \\
(0.004)\end{array}$ & $\begin{array}{c}0.009 \\
(0.008)\end{array}$ & $\begin{array}{c}0.012 \\
(0.010)\end{array}$ \\
\hline Medium Group & & $\begin{array}{c}0.004 \\
(0.025)\end{array}$ & $\begin{array}{l}-0.092 \\
(0.068)\end{array}$ & $\begin{array}{l}-0.053 \\
(0.088)\end{array}$ \\
\hline Big Group & & $\begin{array}{l}0.006 \\
(0.025)\end{array}$ & $\begin{array}{l}-0.106 \\
(0.069)\end{array}$ & $\begin{array}{l}-0.108 \\
(0.090)\end{array}$ \\
\hline $\mathrm{PU}$ & & $\begin{array}{l}-0.010 \\
(0.021)\end{array}$ & $\begin{array}{c}0.065 \\
(0.059)\end{array}$ & $\begin{array}{c}0.091 \\
(0.087)\end{array}$ \\
\hline Medium Group $\times$ PU & & & $\begin{array}{c}0.022 \\
(0.050)\end{array}$ & $\begin{array}{l}-0.056 \\
(0.125)\end{array}$ \\
\hline Big Group $\times$ PU & & & $\begin{array}{c}0.020 \\
(0.050)\end{array}$ & $\begin{array}{c}0.022 \\
(0.127)\end{array}$ \\
\hline Medium Group $\times$ N. Reciprocity & & & $\begin{array}{c}0.015 \\
(0.010)\end{array}$ & $\begin{array}{c}0.008 \\
(0.014)\end{array}$ \\
\hline BIG GRoup $\times$ N. RECIPROCITY & & & $\begin{array}{l}0.018^{*} \\
(0.011)\end{array}$ & $\begin{array}{c}0.019 \\
(0.015)\end{array}$ \\
\hline PU $\times$ N. RECIPROCITY & & & $\begin{array}{c}-0.016^{*} \\
(0.009)\end{array}$ & $\begin{array}{l}-0.021 \\
(0.014)\end{array}$ \\
\hline Medium Group $\times$ PU $\times$ N. Reciprocity & & & & $\begin{array}{c}0.014 \\
(0.021)\end{array}$ \\
\hline BIG GRoup $\times$ PU $\times$ N. RECIPRoCITY & & & & $\begin{array}{c}-0.0004 \\
(0.021)\end{array}$ \\
\hline Constant & $\begin{array}{c}0.470^{* * *} \\
(0.026)\end{array}$ & $\begin{array}{c}0.472^{* * *} \\
(0.032)\end{array}$ & $\begin{array}{c}0.494^{* * *} \\
(0.052)\end{array}$ & $\begin{array}{c}0.482^{* * *} \\
(0.060)\end{array}$ \\
\hline Observations & 2,345 & 2,345 & 2,345 & 2,345 \\
\hline
\end{tabular}


Table C.11: The volunteering choice explained by RISK and all treatment dummies in a linear probability model with robust standard errors

\begin{tabular}{|c|c|c|c|c|}
\hline & \multicolumn{4}{|c|}{ Dependent variable: } \\
\hline & \multicolumn{4}{|c|}{ Volunteering Choice } \\
\hline & $(1)$ & $(2)$ & $(3)$ & $(4)$ \\
\hline RISK & $\begin{array}{l}-0.004 \\
(0.004)\end{array}$ & $\begin{array}{l}-0.004 \\
(0.004)\end{array}$ & $\begin{array}{c}0.005 \\
(0.008)\end{array}$ & $\begin{array}{c}0.006 \\
(0.009)\end{array}$ \\
\hline Medium Group & & $\begin{array}{c}0.003 \\
(0.025)\end{array}$ & $\begin{array}{l}-0.004 \\
(0.056)\end{array}$ & $\begin{array}{l}-0.005 \\
(0.071)\end{array}$ \\
\hline Big Group & & $\begin{array}{c}0.003 \\
(0.025)\end{array}$ & $\begin{array}{c}0.053 \\
(0.057)\end{array}$ & $\begin{array}{c}0.069 \\
(0.071)\end{array}$ \\
\hline $\mathrm{PU}$ & & $\begin{array}{l}-0.011 \\
(0.021)\end{array}$ & $\begin{array}{c}0.022 \\
(0.051)\end{array}$ & $\begin{array}{c}0.032 \\
(0.072)\end{array}$ \\
\hline Medium Group $\times$ PU & & & $\begin{array}{c}0.018 \\
(0.050)\end{array}$ & $\begin{array}{c}0.022 \\
(0.102)\end{array}$ \\
\hline BIG GROUP $\times$ PU & & & $\begin{array}{c}0.014 \\
(0.051)\end{array}$ & $\begin{array}{l}-0.017 \\
(0.100)\end{array}$ \\
\hline MEDIUM GRoup $\times$ Risk & & & $\begin{array}{c}-0.0003 \\
(0.009)\end{array}$ & $\begin{array}{c}0.0002 \\
(0.013)\end{array}$ \\
\hline BIG GROUP $\times$ Risk & & & $\begin{array}{l}-0.013 \\
(0.009)\end{array}$ & $\begin{array}{l}-0.016 \\
(0.013)\end{array}$ \\
\hline $\mathrm{PU} \times \mathrm{RISK}$ & & & $\begin{array}{l}-0.010 \\
(0.008)\end{array}$ & $\begin{array}{c}-0.012 \\
(0.013)\end{array}$ \\
\hline Medium Group $\times$ PU $\times$ Risk & & & & $\begin{array}{l}-0.001 \\
(0.019)\end{array}$ \\
\hline BIG GROUP $\times$ PU $\times$ RISK & & & & $\begin{array}{c}0.007 \\
(0.019)\end{array}$ \\
\hline Constant & $\begin{array}{c}0.556^{* * *} \\
(0.020)\end{array}$ & $\begin{array}{c}0.560^{* * *} \\
(0.028)\end{array}$ & $\begin{array}{c}0.523^{* * *} \\
(0.044)\end{array}$ & $\begin{array}{c}0.519^{* * *} \\
(0.050)\end{array}$ \\
\hline Observations & 2,345 & 2,345 & 2,345 & 2,345 \\
\hline
\end{tabular}


Table C.12: The volunteering choice explained by TRUsT and all treatment dummies in a linear probability model with robust standard errors

\begin{tabular}{|c|c|c|c|c|}
\hline & \multicolumn{4}{|c|}{ Dependent variable: } \\
\hline & \multicolumn{4}{|c|}{ Volunteering Choice } \\
\hline & (1) & $(2)$ & (3) & $(4)$ \\
\hline Trust & $\begin{array}{c}0.001 \\
(0.004)\end{array}$ & $\begin{array}{c}0.001 \\
(0.004)\end{array}$ & $\begin{array}{c}0.004 \\
(0.007)\end{array}$ & $\begin{array}{l}-0.001 \\
(0.009)\end{array}$ \\
\hline Medium Group & & $\begin{array}{c}0.004 \\
(0.025)\end{array}$ & $\begin{array}{l}-0.003 \\
(0.061)\end{array}$ & $\begin{array}{l}-0.031 \\
(0.078)\end{array}$ \\
\hline Big Group & & $\begin{array}{c}0.004 \\
(0.025)\end{array}$ & $\begin{array}{c}0.022 \\
(0.061)\end{array}$ & $\begin{array}{l}-0.028 \\
(0.077)\end{array}$ \\
\hline $\mathrm{PU}$ & & $\begin{array}{l}-0.011 \\
(0.021)\end{array}$ & $\begin{array}{l}-0.022 \\
(0.055)\end{array}$ & $\begin{array}{l}-0.078 \\
(0.080)\end{array}$ \\
\hline Medium Group $\times$ PU & & & $\begin{array}{c}0.020 \\
(0.050)\end{array}$ & $\begin{array}{c}0.082 \\
(0.113)\end{array}$ \\
\hline Big Group $\times$ PU & & & $\begin{array}{c}0.021 \\
(0.051)\end{array}$ & $\begin{array}{c}0.127 \\
(0.112)\end{array}$ \\
\hline Medium Group $\times$ Trust & & & $\begin{array}{l}-0.001 \\
(0.009)\end{array}$ & $\begin{array}{c}0.005 \\
(0.013)\end{array}$ \\
\hline Big Group $\times$ Trust & & & $\begin{array}{l}-0.005 \\
(0.009)\end{array}$ & $\begin{array}{c}0.004 \\
(0.013)\end{array}$ \\
\hline $\mathrm{PU} \times$ TRUST & & & $\begin{array}{l}-0.001 \\
(0.007)\end{array}$ & $\begin{array}{c}0.009 \\
(0.013)\end{array}$ \\
\hline Medium Group $\times$ PU $\times$ Trust & & & & $\begin{array}{l}-0.011 \\
(0.018)\end{array}$ \\
\hline BIG Group $\times$ PU $\times$ Trust & & & & $\begin{array}{l}-0.019 \\
(0.018)\end{array}$ \\
\hline Constant & $\begin{array}{c}0.529^{* * *} \\
(0.023)\end{array}$ & $\begin{array}{c}0.531^{* * *} \\
(0.029)\end{array}$ & $\begin{array}{c}0.526^{* * *} \\
(0.047)\end{array}$ & $\begin{array}{c}0.551^{* * *} \\
(0.053)\end{array}$ \\
\hline Observations & 2,345 & 2,345 & 2,345 & 2,345 \\
\hline
\end{tabular}


Table C.13: The volunteering choice explained by Time PREFEREnCES and all treatment dummies in a linear probability model with robust standard errors

\begin{tabular}{|c|c|c|c|c|}
\hline & \multicolumn{4}{|c|}{ Dependent variable: } \\
\hline & \multicolumn{4}{|c|}{ Volunteering Choice } \\
\hline & $(1)$ & $(2)$ & $(3)$ & $(4)$ \\
\hline Time & $\begin{array}{c}0.021^{* * *} \\
(0.004)\end{array}$ & $\begin{array}{c}0.021^{* * *} \\
(0.004)\end{array}$ & $\begin{array}{c}0.013 \\
(0.009)\end{array}$ & $\begin{array}{l}0.018^{*} \\
(0.010)\end{array}$ \\
\hline Medium Group & & $\begin{array}{c}0.005 \\
(0.025)\end{array}$ & $\begin{array}{c}-0.133^{*} \\
(0.077)\end{array}$ & $\begin{array}{l}-0.092 \\
(0.100)\end{array}$ \\
\hline Big Group & & $\begin{array}{c}0.004 \\
(0.025)\end{array}$ & $\begin{array}{l}-0.106 \\
(0.078)\end{array}$ & $\begin{array}{l}-0.048 \\
(0.100)\end{array}$ \\
\hline $\mathrm{PU}$ & & $\begin{array}{l}-0.012 \\
(0.021)\end{array}$ & $\begin{array}{c}0.038 \\
(0.067)\end{array}$ & $\begin{array}{c}0.109 \\
(0.104)\end{array}$ \\
\hline Medium Group $\times$ PU & & & $\begin{array}{c}0.019 \\
(0.050)\end{array}$ & $\begin{array}{l}-0.071 \\
(0.146)\end{array}$ \\
\hline Big Group $\times$ PU & & & $\begin{array}{c}0.017 \\
(0.050)\end{array}$ & $\begin{array}{l}-0.110 \\
(0.147)\end{array}$ \\
\hline Medium Group $\times$ Time & & & $\begin{array}{l}0.020^{*} \\
(0.011)\end{array}$ & $\begin{array}{c}0.014 \\
(0.014)\end{array}$ \\
\hline Big Group $\times$ Time & & & $\begin{array}{c}0.016 \\
(0.011)\end{array}$ & $\begin{array}{c}0.007 \\
(0.015)\end{array}$ \\
\hline $\mathrm{PU} \times$ Time & & & $\begin{array}{l}-0.010 \\
(0.009)\end{array}$ & $\begin{array}{l}-0.021 \\
(0.015)\end{array}$ \\
\hline Medium Group $\times$ PU $\times$ Time & & & & $\begin{array}{c}0.014 \\
(0.021)\end{array}$ \\
\hline Big Group $\times$ PU $\times$ Time & & & & $\begin{array}{c}0.020 \\
(0.021)\end{array}$ \\
\hline Constant & $\begin{array}{c}0.404^{* * *} \\
(0.030)\end{array}$ & $\begin{array}{c}0.406^{* * *} \\
(0.035)\end{array}$ & $\begin{array}{c}0.460^{* * *} \\
(0.061)\end{array}$ & $\begin{array}{c}0.428^{* * *} \\
(0.071)\end{array}$ \\
\hline Observations & 2,345 & 2,345 & 2,345 & 2,345 \\
\hline
\end{tabular}




\section{Experiment Instructions}

\section{D.1 The Introduction}

Welcome and thank you for your support of our project. In this task, you will rate comments from users of an internet forum. With your help, we will better able to understand and assess the behavior of our users. A more detailed explanation of the task can be found in the section "Your task".

\section{Please note:}

The quality of the data resulting from rating the comments is very important to us. Furthermore, there are a lot of comments from the Internet forum, all of which should be evaluated. To ensure data quality and efficient handling of the tasks, you will be working in a team. Your team consists of [PU: $\mu-s$ to $\mu+s$ members; NPU: exactly $\mu$ members]. You will initially work individually on the task described below.

\section{Your task:}

Below we will show you a series of pictures, each with a comment. These comments come from different users of an internet forum. For each of these comments, we have the following four questions for you:

1. "Is the comment friendly or hostile towards the group which is displayed in the photo?"

We would like to know from you how hostile you find the comment with regard to the topic shown in the picture. You should rate the comments on a scale of 1 to 9 . 1 means very friendly, 9 means very hostile.

[Possible answers: Value in a Likert scale between 1 ("very friendly) to 9 ("very hostile") or "Not possible to rate"] 
In some cases, the comments are difficult to evaluate. Please click on the checkbox "Not to rate" in these cases.

\section{2. "Is the comment addressed to another user?"}

In part, the comments you see are directed towards other users on the internet forum. We are interested in whether the comment is directed towards another user and, if so, whether she agrees or disapproves of the other user. Therefore, we ask you please to answer the following question for each comment: "Is the comment addressed to another user?"

[Possible Answers: "No", "Yes, agreeing", "Yes, rejecting", "Not possible to rate"]

In some cases, the comments are difficult to evaluate. Please click on the checkbox "Not possible to rate" in these cases.

\section{3. "Should the comment be allowed in an online forum?"}

Do you personally think that the comment should be allowed in an internet forum?

[Possible Answers: "No", "Yes", "Not possible to rate"]

\section{4. "Which features apply to the comment?"}

You will also find a list of features below the scale. Please click on any features that you think apply to the comment. If none of the features apply, just do not click on any.

[Possible Answers: "Contains negative prejudices", "Uses racist insults", "Contains offensive, degrading or derogatory words", "Calls for violence, threats or discrimination", "Uses sexist insults" or/and "Sexual orientation or gender is degraded or stigmatized"] 
You will only see each comment once. When you have finished a page, please click on "Next". You will rate a total of 30 comments.

Please press "Next" to start the task. Thanks for your support. 


\section{D.2 The Task}

\section{Kommentar 1 von ingesamt 30 Kommentaren}

Das Bild:

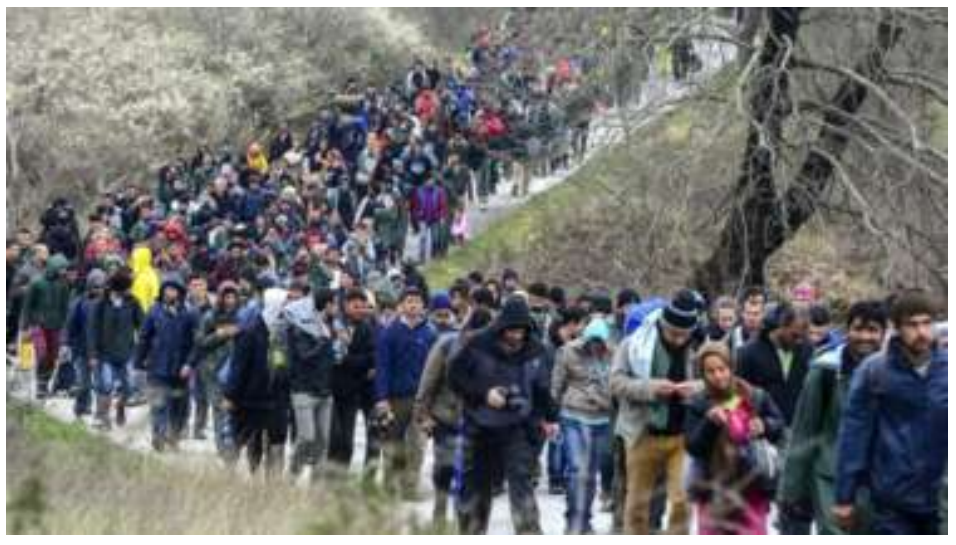

Der Kommentar:

Wir sollten das gemeinsame Wohlergehen der Menschen über ein unreflektiertes temporäres "unwohlsein" stellen.

Ist der Kommentar freundlich oder feindselig gegenüber der im Foto dargestellten Gruppe?

sehr freundlich $\bigcirc 1 \bigcirc 2 \bigcirc 3 \bigcirc 4 \quad \bigcirc 5 \quad \bigcirc 6 \quad 7 \quad 08 \bigcirc 9$ sehr feindselig

Nicht zu bewerten

Richtet sich der Kommentar an einen anderen Nutzer?

$\bigcirc$ Nein $\bigcirc$ Ja, er ist zustimmend $\bigcirc \mathrm{Ja}$, er ist ablehnend

Nicht zu bewerten

Sollte dieser Kommentar in einem Internetforum erlaubt sein?

$\bigcirc$ Nein $\bigcirc$ Ja $\bigcirc$ Ich weiß nicht

Welche Merkmale treffen auf den Kommentar zu?

$\square$ Beinhaltet negative Vorurteile

$\square$ Nutzt rassistische Beleidigungen

$\square$ Beinhaltet beleidigende, erniedrigende oder abwertende Worte

$\square$ Ruft zu Gewalt, Drohungen oder Diskriminierung auf

$\square$ Nutzt sexistische Beleidigungen

$\square$ Die sexuelle Orientierung oder das Geschlecht/Gender wird herabgesetzt oder stigmatisiert

Figure D.1: Screenshot of the task. 


\section{D.3 The Volunteering Decision}

\section{Additional task for securing the data quality in the team}

Thank you for rating the 30 comments. You completed now the main task and will receive $0.90 €$ for it. In total, it took you Time minutes to complete the task. Participants in this task normally need between 7.5 Minutes and 15.0 minutes to rate 30 comments.

We now need exactly one volunteer from your team of [PU: $\mu-s$ to $\mu+s$ person; NPU: exactly $\mu$ person].

\section{Instructions for the additional task in the team:}

To assess the comment ratings in your team better, and to improve data quality, 30 more comments need to be rated by your team.

- All team members receive a bonus of $0.90 €$ each, if one person completes this additional task.

- All persons in your team are offered this additional task.

- It is enough for one person on your team of [PU: $\mu-s$ to $\mu+s$ person; NPU: exactly $\mu$ person] to volunteer. All team members will then receive the bonus payment. The amount of the bonus payment does not increase if more than one person completes the additional task.

- You will also receive the bonus if you do not volunteer, but another person is found.

- If nobody volunteers in your team, nobody will receive a bonus of $0.90 €$.

- Your decision to volunteer in your team or not will not affect your reputation on the Clickworker platform or the money you earned so far.

Do you want to volunteer in your team, which consists of [PU: $\mu-s$ to $\mu+s$ person; NPU: exactly $\mu$ person], and rate the additional 30 comments? [Possible Answers: "Yes" or "No"] 


\title{
Zusatzaufgabe zur Sicherung der Datenqualität im Team
}

\begin{abstract}
Vielen Dank für die Bewertung der 30 Kommentare. Sie haben die Hauptaufgabe damit abgeschlossen und erhalten dafür $0,90 €$. Ingesamt haben Sie 13,46 Minuten für die Aufgabe benötigt. Teilnehmer dieser Aufgabe benötigen normalerweise zwischen 7,5

Minuten und 15,0 Minuten um 30 Kommentare zu bewerten.
\end{abstract}

Wir benötigen jetzt genau einen Freiwilligen aus Ihrem Team von genau 30 Personen.

\section{Anleitung zur Zusatzaufgabe im Team:}

Um eine bessere Einschätzung der Kommentarbewertungen in ihrem Team zu ermöglichen und die Datenqualität zu verbessern, müssen 30 weitere Kommentare von Ihrem Team bewertet werden.

- Alle Teammitglieder erhalten jeweils einen Bonus von 0,9€, wenn eine Person diese zusätzliche Aufgabe absolviert.

- Alle Personen in Ihrem Team bekommen diese Zusatzaufgabe angeboten.

- Es genügt, dass sich eine Person in Ihrem Team von genau 30 Personen freiwillig meldet. Alle Teammitglieder erhalten dann die Bonuszahlung. Die Höhe der Bonuszahlung steigt nicht, wenn mehr als eine Person die Zusatzaufgabe absolviert.

- Sie bekommen den Bonus auch, wenn Sie sich nicht freiwillig melden aber sich eine andere Person findet.

- Wenn sich in Ihrem Team niemand freiwillig meldet, dann bekommt auch niemand einen Bonus von 0,9 $€$.

- Ihre Entscheidung ob Sie sich in Ihrem Team freiwillig melden wollen oder nicht, wird keinen Einfluss auf Ihre Bewertung auf der Clickworker Plattform oder auf Ihr bisher verdientes Geld haben.

Wollen Sie sich in Ihrem Team, das aus genau 30 Personen besteht, freiwillig melden und die $\mathbf{3 0}$ weiteren Kommentare bewerten?

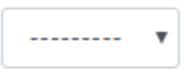

Weiter

Figure D.2: Screenshot of the volunteering decision described in Section 3.3

\section{D.4 Questionnaire Items}

- Risk: "Are you a person who is generally willing to take risks, or do you try to avoid taking risks?"; Scale: 0 = "completely unwilling to take risks"; 10 = "very willing to take risks".

- Time: "In comparison to others, are you a person who is generally willing to give up something today in order to benefit from that in the future, or are you not willing to do so?"; Scale: 0 = "completely unwilling to give up something today"; $10=$ "very willing to give up something today".

- Trust: "As long as I am not convinced otherwise, I assume that people have only the best intentions."; Scale: $0=$ "does not describe me at all"; $10=$ "describes me perfectly". 
- Negative Reciprocity: "Are you a person who is generally willing to punish unfair behavior even if this is costly?"; Scale: $0=$ "not willing at all to incur costs to punish unfair behavior"; 10 = "very willing to incur costs to punish unfair behavior".

- Altruism: "Imagine the following situation: you won 1,000 € in a lottery. Considering your current situation, how much would you donate to charity?"; Values between 0 and 1000 are allowed.

- EFFICIEnCY: "I am more willing to make an effort if many profit from it."; Scale: $0=$ "does not describe me at all"; 10 = "describes me perfectly". 